OPEN ACCESS

Edited by:

Salvatore Salomone,

University of Catania, Italy

Reviewed by:

Serena Boccella,

University of Campania Luigi

Vanvitelli, Italy

Renes Machado,

Federal University of Minas Gerais,

Brazil

*Correspondence:

Vinicio Granados-Soto

vgranados@cinvestav.mx

Jorge Elías Torres-López

jorge.torres@ujat.mx

tORCID:

Janet Murbartián

orcid.org/0000-0001-5776-1067

Vinicio Granados-Soto orcid.org/0000-0003-1038-8400

Jorge Elías Torres-López orcid.org/0000-0001-7677-6313

Crystell Guadalupe Guzmán-Priego orcid.org/0000-0002-8228-1314

Guadalupe del Carmen Baeza-Fores orcid.org/0000-0002-6587-8565

Specialty section:

This article was submitted to Experimental Pharmacology and Drug Discovery,

a section of the journal

Frontiers in Pharmacology

Received: 05 June 2020 Accepted: 02 September 2020 Published: 23 September 2020

Citation:

Baeza-Flores GDC, Guzmán-Priego CG, Parra-Flores LI, Murbartián J, Torres-López JE and Granados-Soto V (2020) Metformin: A

Prospective Alternative for the Treatment of Chronic Pain.

Front. Pharmacol. 11:558474. doi: 10.3389/fphar.2020.558474

\section{Metformin: A Prospective Alternative for the Treatment of Chronic Pain}

\author{
Guadalupe Del Carmen Baeza-Flores ${ }^{1 \dagger}$, Crystell Guadalupe Guzmán-Priego ${ }^{1 \dagger}$, \\ Leonor Ivonne Parra-Flores ${ }^{1}$, Janet Murbartián ${ }^{2 \dagger}$, Jorge Elías Torres-López ${ }^{1,3 * t}$ \\ and Vinicio Granados-Soto ${ }^{4 * T}$ \\ ${ }^{1}$ Laboratorio de Mecanismos de Dolor, División Académica de Ciencias de la Salud, Universidad Juárez Autónoma de \\ Tabasco, Villahermosa, Mexico, ${ }^{2}$ Departamento de Farmacobiología, Cinvestav, South Campus, Mexico City, Mexico, \\ ${ }^{3}$ Departamento de Anestesiología, Hospital Regional de Alta Especialidad "Dr. Juan Graham Casasús", Villahermosa, \\ Mexico, ${ }^{4}$ Neurobiology of Pain Laboratory, Departamento de Farmacobiología, Cinvestav, South Campus, Mexico City, \\ Mexico
}

Metformin (biguanide) is a drug widely used for the treatment of type 2 diabetes. This drug has been used for 60 years as a highly effective antihyperglycemic agent. The search for the mechanism of action of metformin has produced an enormous amount of research to explain its effects on gluconeogenesis, protein metabolism, fatty acid oxidation, oxidative stress, glucose uptake, autophagy and pain, among others. It was only up the end of the 1990s and beginning of this century that some of its mechanisms were revealed. Metformin induces its beneficial effects in diabetes through the activation of a master switch kinase named AMP-activated protein kinase (AMPK). Two upstream kinases account for the physiological activation of AMPK: liver kinase B1 and calcium/ calmodulin-dependent protein kinase kinase 2. Once activated, AMPK inhibits the mechanistic target of rapamycin complex 1 (mTORC1), which in turn avoids the phosphorylation of p70 ribosomal protein S6 kinase 1 and phosphatidylinositol 3kinase/protein kinase B signaling pathways and reduces cap-dependent translation initiation. Since metformin is a disease-modifying drug in type 2 diabetes, which reduces the $\mathrm{mTORC} 1$ signaling to induce its effects on neuronal plasticity, it was proposed that these mechanisms could also explain the antinociceptive effect of this drug in several models of chronic pain. These studies have highlighted the efficacy of this drug in chronic pain, such as that from neuropathy, insulin resistance, diabetic neuropathy, and fibromyalgia-type pain. Mounting evidence indicates that chronic pain may induce anxiety, depression and cognitive impairment in rodents and humans. Interestingly, metformin is able to reverse some of these consequences of pathological pain in rodents. The purpose of this review was to analyze the current evidence about the effects of metformin in chronic pain and three of its comorbidities (anxiety, depression and cognitive impairment).

Keywords: anxiety, AMPK activation, chronic pain, metformin, depression, neuropathic pain, diabetic neuropathy, diabetes 


\section{INTRODUCTION}

Acute pain is considered an alarm system for protecting body integrity, while chronic pain may serve an adaptative role (Crook et al., 2014; Lister et al., 2020). In spite of its role, chronic pain is a major health problem around the world with a prevalence up to 50\% (Fayaz et al., 2016; Manion et al., 2019). Chronic pain (defined in humans as the pain of more than three months) describes pain such as neuropathic pain, low-back pain, osteoarthritis, traumatic injury and postoperative pain, among others. Interestingly, chronic pain may induce anxiety and depression in rodents and humans (Wang et al., 2019; Zhou et al., 2019). In addition, chronic pain leads to cognitive impairment (Zhou et al., 2016; Shiers et al., 2018). Acute pain is mainly treated with non-steroidal anti-inflammatory drugs (NSAIDs) and/or opioids. In contrast, chronic pain is not easy to treat. Currently the pharmacotherapy for chronic pain includes tricyclic antidepressants (amitriptyline and nortriptyline), anticonvulsants (gabapentin and pregabalin) and opioids (tramadol and morphine). However, this pharmacotherapy has limited efficacy and several side effects. Although metformin was discovered in the 1940s, its properties as an anti-diabetic drug were known in 1957 (Sterne, 1957). There is evidence that metformin reduces weight, hyperglycemia and glycosylated hemoglobin in type 2 diabetic patients (Clarke and Duncan, 1968; Clarke and Campbell, 1977; Campbell and Howlett, 1995; DeFronzo and Goodman, 1995; Stumvoll et al., 1995; Johansen, 1999; Hundal et al., 2000) with a favorable risk-benefit assessment in patients with diabetes mellitus (Howlett and Bailey, 1999). In addition, a large multicenter study showed that metformin improves long-lasting metabolic effects and reduces cardiovascular risk (UKPDS, 1998). Later, several comprehensive reviews have been documented the effects of metformin in diabetes (Hermann, 1979; Vigneri and Goldfine, 1987; Dunn and Peters, 1995; Garber, 1997; Maruthur et al., 2016; Markowicz-Piasecka et al., 2017; Rena et al., 2017).

\footnotetext{
Abbreviations: $\alpha_{5} \mathrm{GABA}_{\mathrm{A}}$ receptor, $\alpha_{5}$ subunit containing $\mathrm{GABA}_{\mathrm{A}}$ receptor; $4 \mathrm{E}-$ $\mathrm{BP} 1$, eukaryotic translation initiation factor $4 \mathrm{E}$ binding protein 1; AMPK, AMPactivated protein kinase; ASIC3, acid-sensing ion channels 3; ATF3, Activating factor transcription 3; CaMKK2, Calcium/calmodulin-dependent protein kinase kinase 2; CFA, Complete Freund's adjuvant; $\mathrm{C}_{\max }$, peak plasma concentration; DRG, dorsal root ganglia; eIF2 $\alpha$, eukaryotic translation initiation factor 2 subunit $\alpha$; eIF $2 \alpha^{\text {Ser51 }}$, eukaryotic translation initiation factor $2 \alpha$ phosphorylated in serine 51; eIF4F, eukaryotic translation initiation factor $4 \mathrm{~F}$; ERK, extracellular regulated protein kinase; GLUT1, glucose transporter 1; GLUT4, glucose transporter 4; IL18 , Interleukin-18; IL-1 $\beta$, interleukin-1 $\beta$; IPMK, Inositol polyphosphate kinase; ISR, integrated stress response; LKB1, Liver kinase B1; MATE1, multidrug and toxin extrusion protein 1 ; MATE $2 \mathrm{~K}$, multidrug and toxin extrusion protein $2 \mathrm{~K}$; mTORC1, mammalian target of rapamycin complex 1; NF- $\mathrm{KB}$, nuclear factor kappa B subunit; NGF, nerve growth factor; OCT1, organic cation transporter 1; OCT3, organic cation transporter 3; p70S6K1, p70 ribosomal protein S6 kinase1; $\mathrm{PGE}_{2}$, Prostaglandin $\mathrm{E}_{2}$; PI3-K/Akt, phosphatidylinositol 3-kinase/protein kinase B; PKA, AMP-dependent protein kinase A; PMAT, plasma membrane monoamine transporter; p-STAT3, phosphorylated signal transducer and activators of transcription 3; SCI, spinal cord injury; SNI, spared nerve injury; $\mathrm{SNL}$, spinal nerve ligation; STAT3, signal transducer and activator of transcription 3; $\mathrm{t}_{1 / 2}$, Half-life; TASK-3, tandem pore domain acid-sensitive $\mathrm{K}^{+}$channel 3 ; TG, trigeminal ganglia; $\mathrm{T}_{\max }$, time to reach the maximal concentration; TRPA1, transient receptor potential ankyrin 1.
}

Recently, many pre-clinical studies have demonstrated the antinociceptive effects of metformin in rodents. Since this drug is a disease-modifying drug in type 2 diabetes, it is likely that it may share these properties to reduce pain and its comorbidities. Here, we assess the current state of evidence regarding the effects of metformin in chronic pathological pain and two of its comorbidities (anxiety/depression and cognitive impairment). Data strongly suggest that metformin could open a new avenue for the treatment of pathological pain and some of its associated comorbidities.

\section{MECHANISMS OF ACTION OF METFORMIN}

There is evidence that metformin decreases hepatic glucose production (Stumvoll et al., 1995; Hundal et al., 2000) and hepatic lipids (Lin et al., 2000), whereas it enhances myocyte glucose uptake (Hundal et al., 1992; Galuska et al., 1994). Although these effects of metformin have been known for many years, the underlying mechanisms remained unknown until 2001. AMP-activated protein kinase (AMPK) is a heterotrimeric serine/threonine enzyme composed of a catalytic $\alpha$ subunit and two regulatory $(\beta, \gamma)$ subunits (Hardie et al., 1998; Kemp et al., 1999). There are two isoforms of the $\alpha$ and $\beta$ subunits and three isoforms of the $\gamma$ subunit, giving twelve possible combinations of the heterotrimeric $\alpha \beta \gamma$ AMPK complex. Currently, two upstream kinases account for the physiological activation of AMPK: liver kinase B1 (LKB1) and $\mathrm{Ca}^{2+} / \mathrm{CaM}$-dependent protein kinase kinase 2 (CaMKK2). AMPK is activated by phosphorylation at threonine 172 in the $\alpha$-catalytic subunit by LKB1 (Hawley et al., 2003; Woods et al., 2003; Shaw et al., 2004). In addition, AMPK is activated independently by direct binding with CaMKK2 (Green et al., 2011; Fogarty et al., 2016). Once phosphorylated/activated, AMPK phosphorylates and regulates key enzymes involved in metabolism and transcription factors that regulate gene expression. By that time, it was already known that AMPK activation led to stimulation of hepatic fatty acid oxidation and ketogenesis, inhibition of cholesterol synthesis, triglyceride synthesis, inhibition of adipocyte lipolysis and lipogenesis. Based on these actions, it was postulated in 1999 that activation of AMPK signaling could be the mechanism of action of metformin in the treatment of type 2 diabetes (Winder and Hardie, 1999). Then, the group of Zhou et al. reported for the first time a mechanism to explain the effects of metformin in diabetes. They discovered that metformin was able to induce its anti-diabetic effects by activation of AMPK in hepatocytes. This activation diminished the expression of lipogenic genes, promoted glucose uptake and suppressed SREBP-1 (insulin-stimulated transcription factor implicated in the pathogenesis of insulin resistance and type 2 diabetes) (Zhou et al., 2001). Metformin also inhibited mitochondrial respiratory chain complex I (Owen et al., 2000), which in turn guided to a reduction in cellular energy status and to up-regulation of the plasma-membrane glucose transporters (GLUT) 1 and 4 
(Hundal et al., 1992; Fischer et al., 1995). This effect depended on the presence of LKB1 (Shaw et al., 2005). Others confirmed the effects of metformin on AMPK in humans (Musi et al., 2002). Later, other researchers found that AMPK activation inhibited in a mammalian target of rapamycin complex 1 (mTORC1)-dependent fashion phosphorylation of p70 ribosomal protein S6 kinase1 (p70S6K1) (Kimura et al., 2003) and phosphatidylinositol 3-kinase/protein kinase B (PI3-K)/Akt signaling pathway (Tzatsos and Kandror, 2006). Likewise, it was reported that metformin-mediated AMPK activation led to inhibition of mTORC1, p70S6K and 4E-BP1 and to reduction of cap-dependent translation initiation (Dowling et al., 2007). More recently, it was found that AMPK activation by metformin is abated in cells lacking inositol polyphosphate multikinase (IPMK), suggesting that LKB1 requires activation by IPMK to phosphorylate AMPK (Bang et al., 2014).

In contrast, other reports have described that metformin may induce its effects in an AMPK-independent manner (Gawler et al., 1989; Yu et al., 1994; Foretz et al., 2010; Miller et al., 2013). There is evidence that metformin may induce its effects by inhibiting the effects of glucagon, AMP-dependent protein kinase A (PKA) activity and phosphorylation of PKA substrates in vitro (Miller et al., 2013).

\section{EFFECTS OF METFORMIN ON PAIN}

\section{Neuropathic Pain}

Neuropathic pain is caused by a lesion or disease of the somatosensory nervous system (Jensen et al., 2011). This pain results from traumatic nerve, spinal cord, or brain injury, as well as diabetes, human immunodeficiency virus, and postherpetic viral infection or with multiple sclerosis, cancer or chemotherapeutic drugs. Neuropathic pain is notoriously resistant to the actions of NSAIDs and opioids, whereas other drugs have only partial effects (Finnerup et al., 2010; Finnerup et al., 2015).

Previous studies have demonstrated that mTORC1 is a regulator of protein synthesis. Of note, mTORC1 signaling can be inhibited by rapamycin, thus preventing downstream signaling (Hay and Sonenberg, 2004; Takei et al., 2004; Zhang et al., 2014). By controlling protein translation, mTORC1 regulate the activity of sensory neurons in the periphery and central nervous system (Asante et al., 2009; Géranton et al., 2009). Reinforcing this, mTORC1 and their downstream targets of the translational machinery are localized in a subset of A-fiber nociceptors (Klann and Dever, 2004; Piper and Holt, 2004; Raab-Graham et al., 2006; Jiménez-Díaz et al., 2008; Obara et al., 2015). Accordingly, the mTORC1 inhibitor rapamycin reduces capsaicin-, nerve injury- or spinal cord injury-induced hypersensitivity in rodents (Jiménez-Díaz et al., 2008; Codeluppi et al., 2009; Géranton et al., 2009). Moreover, intrathecal administration of rapamycin reduces formalin-induced painrelated behavior (Kim et al., 1998; Price et al., 2007; Asante et al., 2009). These data suggest that the mTORC1 pathway plays a key role in the translation and protein synthesis in primary afferent neurons which maintains chronic plasticity in pathological pain. With these antecedents, the group of Price and co-workers was the first to demonstrate the antinociceptive effect of metformin in pain (Melemedjian et al., 2011). They found that treatment with metformin starting 2- or 7-weeks post-nerve injury completely reversed spared nerve injury (SNI)induced tactile allodynia in mice. Moreover, metformin diminished spinal nerve ligation (SNL)-induced tactile allodynia in rats (Melemedjian et al., 2011). Authors of this study reported that metformin was able to activate AMPK and inhibited the mTORC1 pathway in mouse trigeminal (TG) neurons. Likewise, metformin reversed nerve growth factor (NGF)-induced hyperexcitability of mouse TG neurons in culture. In addition, metformin inhibited eukaryotic translation initiation factor $4 \mathrm{~F}$ (eIF4F) formation in primary cultures of TG and dorsal root ganglia (DRG) neurons treated with NGF. These data demonstrate that metformin suppresses nerve injuryinduced aberrant translation pathways in primary afferent neurons, reduces neuronal excitability and inhibits pain in models of neuropathic pain in mice and rats (Melemedjian et al., 2011). In support of this, other studies from the same group reported that daily injection with metformin in mice with SNI 7-weeks post-injury reverses tactile allodynia by diminishing mTORC1 and extracellular regulated protein kinase (ERK) activation pathways in sensory neurons. This antiallodynic effect of metformin persisted for at least 2 months (Melemedjian et al., 2013a). Since ERK activation in the peripheral nervous system is a well-known mechanism for increasing the excitability of nociceptors (Ji et al., 2009), the observed effects of metformin may be due, in part, to the inhibition of ERK-induced phosphorylation of Nav1.7 sodium channels (Stamboulian et al., 2010). Interestingly, repeated administration of metformin reduces tactile allodynia and increases apolipoprotein E expression, which is linked to functional recovery after nerve injury (Melemedjian et al., 2013a; Melemedjian et al., 2013b). Furthermore, metformin was able to prevent other neuropathic pain types in rodent models such as cisplatin-, paclitaxel-and bortezomib-induced tactile allodynia (Mao-Ying et al., 2014; Wei et al., 2017; FalcãoPereira et al., 2019; Ludman and Melemedjian, 2019) or spinal cord injury (Zhang et al., 2017; Liu et al., 2019; see Table 1). Some of these effects are mediated by reducing elevated cytokines levels (interleukin-1 $\beta$ and TNF $\alpha$ ), suppressing the expression of the signal transducer and activator of transcription 3 (p-STAT3) and inhibiting activation of microglia and astrocytes at the spinal cord (Afshari et al., 2018; Ge et al., 2018). Other authors have demonstrated that metformin diminishes neuropathic pain, enhances autophagy markers (LC3 and beclin1) and promotes accumulation of autophagy substrate protein p62 in the ipsilateral spinal cord (Weng et al., 2019). The Price's group found recently that AMPK activation inhibits nascent protein synthesis and increases P-body formation (RNA granules) in DRG neurons. They also reported that neuropathic pain decreases P-bodies in the DRG, consistent with an increased mRNA translation, in mice, whereas that metformin restores these effects in neuropathic animals (Paige et al., 2019). These 
Spared nerve injury (SNI, mice) Reversed mechanical allodynia induced and spinal nerve ligation (SNL, by nerve injury

rats

Inflammatory pain (formalin test

and zymosan $A$ test)

Spared nerve injury, SNI (mice) Spinal nerve ligation, SNL (rats)

Nerve injury (SNI, mice and

Reduced tactile allodynia

SNL, rats)

Chemotherapy-induced

peripheral neuropathy by

cisplatin and paclitaxel

Diabetic neuropathy induced by Reduced thermal hyperalgesia and

streptozotocin (STZ)

Diabetic neuropathy induced by Reduced diabetes-induced mechanica STZ

High fat diet/STZ (HFD/STZ) insulin resistance

Chronic inflammatory pain induced by compound $C$

STZ-and methylglyoxal-induced pain

Post-surgical pain (plantar incision)

Chemotherapy-induced neuropathy (bortezomib) Spinal cord injury (SCI) Prevented development of inflammatory

Diminished tactile allodynia

Prevented the development mechanical allodynia actile allodynia

hyperalgesia, cold allodynia

Prevented mechanical hyperalgesia

in sensory neurons hypersensitivity and hyperalgesic

Chronic constriction injury (CCI) Chronic treatment reversed established

Spared-nerve injury (SNI)

Spinal cord injury (SCl)

Type2 diabetes neuropathy

Type2 diabetes neuropathy induced by neonatal STZ
Reduced thermal hyperalgesia induced by compound $\mathrm{C}$

Inhibited methylglyoxal-induced nociception and STZ-induced tactile allodynia

Inhibited incision-evoked mechanical priming induced by PEG Reduced bortezomib-induced tactile allodynia

Improvement of functional locomotor activity after $\mathrm{SCl}$ thermal hyperalgesia

Increased p-AMPK, restored serum levels of IL-1 $\beta$ and IL-18

No determined

AMPK activation in DRG neurons in culture

Prevented the increase of RAGE induced by bortezomib in spina dorsal horn

Activated AMPK and inhibited mTOR signaling. Improved functiona recovery through autophagy flux stimulation

Activated AMPK and suppressed p-STAT3 expression

Inhibited lba-1 and GFAP expression induced by CCI in spina

dorsal horn

Restored axon initial segment in infralimbic cortex

ersed the pain-related cognitive impairment in male mice

Decreased sensitivity to mechanical and Attenuated TNF $\alpha$ and IL-1 $\beta$ levels in spinal cord Reduced tactile allodynia

Decreased number of synapses in the $L 5$ segment of spinal dorsal

Alleviated tactile allodynia

No determined thermal allodynia induced by SCl
AMPK activation. Inhibited mTOR pathway and the elF4F complex formation in TG neurons.

Reduced nascent protein synthesis in sciatic nerve

AMPKo2 subunit activation

AMPK activation. Prevented rapamycin-induced ERK activation and Male ICR and C57BL/6 mice suppressed mTOR/p70S6 kinase signaling

Increased Apolipoprotein E expression in sciatic nerve

Reduced loss of peripheral nerve endings of intra-epidermal nerve fibers

\section{No determined}

Decreased malondialdehyde and glycation end products levels in blood. Increased superoxide dismutase activity and expression of p-AMPK, PGC- $1 \alpha$, Sirt-3, and nNOS in sciatic nerves

No determined

Male ICR and C57BL/6 mice Male Sprague-Dawley rats

Male C57BL/6 mice Male Sprague-Dawley rats

Male ICR mice

Male Spraque-Dawley rats

C57BI/6J mice

Male Wistar rats

Male Sprague-Dawley rats

Male Sprague-Dawley rats

Male C57/BL6/J mice

Male Wistar rat

Male ICR mice

Male Sprague-Dawley rats. Male C57 mice

Female Sprague-Dawley rats

Male Sprague-Dawley rats

Male and Female C57BL/6J mice

Male Sprague-Dawley rats

Male adult Sprague-Dawley
$200 \mathrm{mg} / \mathrm{kg} /$ day for 7 days, ip (Melemedjian et al., 2011)

100 mg/kg, ip (Russe et al. 2013)

$200 \mathrm{mg} / \mathrm{kg} /$ day for 7 days, ip (Melemedjian et al., 2013a)

$200 \mathrm{mg} / \mathrm{kg} /$ day for 7 days, ip (Melemedjian et al., 2013b) $200 \mathrm{mg} / \mathrm{kg} /$ day for 7 days, ip (Mao-Ying et al., 2014)

$500 \mathrm{mg} / \mathrm{kg} /$ day for 4-6 weeks po (Yadav et al., 2014) 30-500 mg/kg, ip (Ma et al., 2015)

$200 \mathrm{mg} / \mathrm{kg} /$ day for 5 weeks, po (Byrne et al., 2015)

$100 \mathrm{ng} / \mathrm{kg} /$ day for 1 week, ip (Bullón et al., 2016) $250 \mathrm{mg} / \mathrm{kg}$, sc (Huang et al., 2016)

30-200 mg/kg/day for 4 days, ip (Burton et al., 2017)

25-50 $\mu \mathrm{g} / 10 \mu \mathrm{l} /$ day, for 10 days it (Wei et al., 2017)

$50 \mathrm{mg} / \mathrm{kg} /$ day, ip (Zhang et al. 2017)

$200 \mathrm{mg} / \mathrm{kg} /$ day for 10 days, ip (Ge et al., 2018)

$200 \mathrm{mg} / \mathrm{kg} /$ day for 7 days, ip Shiers et al., 2018

10-100 mg/kg, ip (Afshari et al., 2018)

$200 \mathrm{mg} / \mathrm{kg} /$ day for 28 days, po (Lin et al., 2018)

$200 \mathrm{mg} / \mathrm{kg} /$ day for 2 weeks, po (Barragán-Iglesias et al., 2018) 
Methylglyoxal-induced pain.

Type1 diabetes induced by STZ

\section{Spared nerve injury (SNI)}

Nociceptive response and chronic constriction injury (CCI) Nerve injury (SNL)

Nerve injury (SNI)

\section{Neuropathy induced by}

chemotherapy (bortezomib)

Neuropathic pain by fructoseinduced insulin resistance Radiculopathy by lumbar disc herniation (LDH)

Visceral Allodynia induced by

LPS

Pain-related hypersensitivity to heat and mechanical stimuli. Capsaicin and formalin test

Complex regional pain syndrome fracture model

\section{Reduced tactile allodynia}

Prevented and reverts SNI-induced mechanical and cold hypersensitivity Increased latency to hot-plate test.

Attenuated mechanical allodynia Attenuated SNL-induced mechanical and thermal hyperalgesia

Inhibited nascent protein synthesis and increased processing-body formation in DRG obtained from SNI mice Prevented development of bortezomibinduced mechanical allodynia

Acute and chronic treatment reduced tactile allodynia

Alleviated LDH-induced pain hypersensitive behaviors

Reduced visceral allodynia

Attenuated pain-related hypersensitivity in Cntnap2 $2^{-/}$mice

Reduced mechanical allodynia
AMPK activation

Reduced elF2 $\alpha^{\text {Ser51 }}$ phosphorylation in IB4+ DRG neurons

Decreased microglial

activation in dorsal horn from male but not female mice

Naltrexone partially attenuated the antinociceptive effect of metformin

Prevented SNL-induced apoptosis. Enhanced autophagy markers LC3 and beclin1 in dorsal horn

Increased levels of Rck/p54 containing RNA granules in DRG in Male ICR mice culture

Reduced levels of hypoxia-inducible factor 1 alpha (HIF1A) in DRG Male ICR mice limiting the translation of hypoxia-inducible factor $1 \alpha(\mathrm{HIF} 1 \mathrm{~A})$

Chronic treatment reversed fructose-induced changes in Insulin receptor $\beta$, ASIC3, anoctamin-1, and ATF3 expression AMPK activation. Suppressed mTOR/p70S6K signaling in DRG neurons

AMPK activation, nitric oxide, and central D2 receptors

Restored the hyperactive Akt-mTOR signaling in DRG neurons from Cntnap2 ${ }^{-/-}$mice

No determined
Male elF4E $\mathrm{S}^{209 \mathrm{~A}}$ and $\mathrm{C} 57 \mathrm{BL} / 6 \quad 200 \mathrm{mg} / \mathrm{kg} /$ day for 10 days, po mice.

Male Wistar rats

Male and female mice (Barragán-Iglesias et al., 2019)

$200 \mathrm{mg} / \mathrm{kg} /$ day for 7 days, ip (Inyang et al., 2019)

Female Swiss mice

500 or $1000 \mathrm{mg} / \mathrm{kg}$, po (Augusto et al., 2019)

$5 \mathrm{mg} / \mathrm{kg} /$ day, ip

(Weng et al., 2019)

200 mg/kg, ip (Paige et al.,

2019)

$150 \mathrm{mg} / \mathrm{kg}$, ip

(Ludman and Melemedjian,

2019)

Male Wistar rats

Male Wistar rats

Male Sprague-Dawley rats

50-200 mg/kg/day, for 4 weeks, po (García et al., 2019)

$250 \mathrm{mg} / \mathrm{kg} /$ day, ip (Liu et al. 2019)

5-50 $\mathrm{mg} / \mathrm{kg} /$ day for 3 days, ip (Nozu et al., 2019)

$200 \mathrm{mg} / \mathrm{kg} /$ day for 2 days, ip (Xing et al., 2020) like 2 knock-down mice (Cntnap2 ${ }^{-/}$)

C57BL/6J female mice Das et al., 2020

MTOR. mammalian target of rapamycin; elF4F, eukaryotic translation initiation factor 4F; PGC-1 $\alpha$, peroxisome proliferator-activated receptor gamma coactivator-1 $\alpha$; Sirt-3, Sirtuin 3; $n N O S$, neuronal nitric oxide synthase; ERK, extracellular regulated protein kinase: IL-1 $\beta$ interleukin-1 B; p-STAT3, signal transducers and activators of transcription 3; lba-1, ionized calcium binding adapter 1; GFAP, glial fibrillary acid protein; LC3, autophagy-related protein: Rck/p54, P body marke and translational repressor/decapping activator; ASIC3, acid-sensing ion channel 3; ATF3, activating transcription factor 3. 
data add to the evidence that metformin induces its antiallodynic effects by reducing the aberrant translation induced by nerve injury. Of note, the effect of metformin in neuropathic pain is sexually dimorphic (Inyang et al., 2019). Although metformin is able to activate AMPK at the same extent in neurons and microglia of male and female rats, this drug does not affect nerve injury-induced neuropathic pain in female rats. Authors suggest that this divergence could be due to the OCT2 expression between males and females (Inyang et al., 2019).

\section{Insulin Resistance}

Pre-diabetes represents the earliest stage of glucose dysregulation and precedes the development of overt type 2 diabetes. Several studies have found that nerve injury-induced neuropathic pain develops before the establishment of high blood glucose levels (hyperglycemia) (Ziegler et al., 2008; Ziegler et al., 2009; Papanas and Ziegler, 2012; Lee et al., 2015). Metabolic syndrome is the aggregation of dyslipidemia, reduced high-density lipoprotein cholesterol, central obesity, insulin resistance (prediabetes or diabetes) and hypertension (Stino and Smith, 2017). Mounting evidence demonstrates that high-fat diet can serve as experimental model of obesity, increased fat mass, and insulin resistance (Guilford et al., 2011; Groover et al., 2013; Lupachyk et al., 2013; Cooper et al., 2016; Cooper et al., 2018). High-fat diet increases body weight, fat deposition, mildly increases blood glucose and induces hyperinsulinemia and tactile allodynia (Groover et al., 2013; Lupachyk et al., 2013; Cooper et al., 2016; Cooper et al., 2018; Prakash et al., 2020). Accordingly, metformin counteracts these effects by AMPK activation and transforming growth factor- $\beta 1$ signaling inhibition in white adipose tissue of rodents and humans (Luo et al., 2016). Interestingly, regular exercise promotes weight reduction and antinociception by activation of AMPK (King-Himmelreich et al., 2017; Slivicki et al., 2019). Likewise, caloric restriction reduces tactile allodynia by stimulating AMPK-mediated autophagy (Coccurello et al., 2018), whereas ketogenic diet induces accumulation of energy by products such as AMP and ADP that in turn activate AMPK (Xiao et al., 2007). All these interventions have a common mechanism of action, activation of AMPK. Several studies suggest that AMPK activation reduces eukaryotic translation initiation factor 2 subunit $\alpha$ (eIF2 $\alpha$ ) phosphorylation in several cell types (Dong et al., 2010; Liang et al., 2013; Boß et al., 2016). Since eIF $2 \alpha$ regulates ternary complex availability (eIF4F complex) (Trinh and Klann, 2013), it has been suggested that metformin also reduces eIF $2 \alpha$-dependent translation initiation (Price and Géranton, 2009; Khoutorsky and Price, 2018; Uttam et al., 2018; Megat and Price, 2018). A recent study from our laboratory shows that metformin diminishes chronic fructoseinduced tactile allodynia (a model of insulin resistance). Moreover, the same study demonstrates that metformin reduces ATF3 (nerve injury marker), anoctamin-1 and acid-sensing ion channels 3 (ASIC3), whereas it restores insulin receptor- $\beta, \alpha_{5}$ subunit containing $\mathrm{GABA}_{\mathrm{A}}$ receptors $\left(\alpha_{5} \mathrm{GABA}_{\mathrm{A}}\right.$ receptors) receptors and tandem pore domain acid-sensitive $\mathrm{K}^{+}$channel 3 (TASK-3) protein expression in DRG and sciatic nerve (García et al., 2019). Whether metformin induces these effects by activating AMPK is not known.

\section{Diabetic Neuropathy}

Type 2 diabetes is recognized as a global epidemic with an incidence that continues to rise. Diabetic neuropathy is the most common cause of neuropathy worldwide. This pathology affects approximately half of patients with diabetes and it increases with age. The painful symptoms of diabetic neuropathy are commonly severe and often lead to depression, anxiety, sleep disorders and reduced quality of life (Pop-Busui et al., 2017). To date, there is not an effective disease-modifying pharmacotherapy to treat the condition. However, several preclinical studies suggest that metformin or other AMPK activators could be used for the treatment of diabetic neuropathy. For instance, it has been shown that metformin diminishes diabetes-induced mechanical hyperalgesia, heat hyperalgesia and cold allodynia and restores streptozotocin-induced changes in hyperglycemia, weight loss, glucose intolerance, reduction of nerve conduction velocity, malondialdehyde, glycation end-products levels, glycosylated hemoglobin levels and superoxide dismutase activity (Yadav et al., 2014; Byrne et al., 2015; Ma et al., 2015; Hasanvand et al., 2016; Barragán-Iglesias et al., 2018; García et al., 2019). Since hyperglycemia leads to formation of methylglyoxal (Bierhaus et al., 2012; Jack et al., 2012) and oxidative stress, it is likely that streptozotocin induces nociception in rats by activating the integrated stress response (ISR) trough reducing the activity of AMPK (Barragán-Iglesias et al., 2019). Accordingly, systemic administration of metformin inhibits paw-injected methylglyoxal-induced nociception, blocks streptozotocininduced tactile allodynia (Huang et al., 2016; Barragán-Iglesias et al., 2019) and activates AMPK (Melemedjian et al., 2011; Ma et al., 2015). It has been proposed that hyperglycemia-derived methylglyoxal depends on activation of Nav1.8 sodium and transient receptor potential ankyrin 1 (TRPA1) channels (Bierhaus et al., 2012; Huang et al., 2016). Authors suggest that methylglyoxal could also activate the RAGE/STAT3 signaling pathway in dorsal horn, which in turn participates in central sensitization and persistent pain (Wei et al., 2017). These effects, however, are reached at high methylglyoxal concentrations. Our group has found that low concentrations of methylglyoxal stimulate the ISR and increases eIF $2 \alpha^{\text {Ser51 }}$ phosphorylation in IB4+ nociceptive neurons of the DRG of mice in vivo and in vitro. In support of this, the specific inhibitor (ISRIB) of the ISR diminishes eIF2 $\alpha^{\text {Ser51 }}$ phosphorylation and reduces and reverts methylglyoxal-induced nociception and also reduces type 1 diabetes-induced neuropathic pain in mice and rats. Interestingly, the AMPK activator drug metformin also lessens eIF $2 \alpha^{\text {Ser51 }}$ phosphorylation (Barragán-Iglesias et al., 2019). These data imply that metformin can decrease the effects of methylglyoxal on pain by reducing eIF2 $\alpha^{\text {Ser51 }}$ phosphorylation in an AMPK-dependent manner (see Table 1). Taken together, data suggest that metformin behaves as a disease-modifying drug in insulin resistance- and experimental diabetes-induced pathological pain.

\section{Inflammatory Pain}

Although acute inflammatory pain is essential for protecting our bodies from potential damage, chronic inflammatory pain, which 
lasts for 3 months or longer, serves an adaptative role but still represents a pathological disease. Up to $50 \%$ of patients who undergo surgical procedures develop chronic pain (Johansen et al., 2012). It is believed that neuronal plasticity consists of peripheral sensitization in DRG neurons and TG and central sensitization of neurons in the spinal cord and brain (Basbaum et al., 2009; Luo et al., 2014). These processes are promoted by descending facilitatory pathways and central neuroinflammation, which mediate the persistence and chronicity of pain conditions (Ji et al., 2013).

Inhibition of spinal mTOR with rapamycin or metformin reduces carrageenan-, compound C (AMPK inhibitor)- or complete Freund's adjuvant (CFA)-induced hyperalgesia and allodynia and restores all changes (up-regulation of mTORC1, p70S6K, 4E-BP1, NF- $\kappa \beta$ and cytokines) induced by activation of the mTOR signaling (Norsted-Gregory et al., 2010; Bullón et al., 2016; Xiang et al., 2019). These data suggest that the mTORC1 signaling also participates in inflammatory pain, while AMPK acting upstream reduces pain and carrageenan-induced longlasting neuronal plasticity. Other studies have found that systemic administration of metformin prevents surgical incision-induced tactile allodynia and $\mathrm{PGE}_{2}$ injection-induced development of hyperalgesic priming in mice by activating AMPK (Burton et al., 2017). Thus, metformin is effective in reducing the transition to a chronic pain state. Interestingly, other AMPK activators, like resveratrol (Dasgupta and Milbrandt, 2007), also reduce tactile allodynia and inhibit hyperalgesic priming. These data add to a body of evidence that AMPK activation reduces development of acute tactile allodynia resulting from tissue injury (Tillu et al., 2012; Russe et al., 2013; Bullón et al., 2016), diminishes the excitability of nociceptors (Melemedjian et al., 2011; Tillu et al., 2012) and prevents the development of hyperalgesic priming (Mejia et al., 2016, see Table 1). Reinforcing this, metformin is not able to induce antinociception in $\mathrm{AMPK} \alpha_{2} \mathrm{KO}$ mice (Russe et al., 2013). Interestingly, the antinociceptive effect of metformin is similar to that of exercise. Exercise leads to the increase of anandamide that in turn activates AMPK to induce antinociception (KingHimmelreich et al., 2017). This mechanism may also explain the effect of exercise in several types of pain (Slivicki et al., 2019).

\section{Pain in Humans}

There are only a few studies assessing the effect of metformin in human beings. One retrospective study found that treatment with metformin in 46 diabetic patients with lumbar radiculopathy pain show lower levels of radiculopathy pain (Taylor et al., 2013). There is evidence to support that alterations in AMPK in fibroblasts from fibromyalgia patients could play an important role in this pathology. These alterations include diminished AMPK phosphorylation, decreased mitochondrial biogenesis, reduced oxygen consumption, decreased antioxidant enzymes expression levels and mitochondrial dysfunction. In these conditions, metformin is able to decrease mitochondrial dysfunction in fibroblasts from fibromyalgia patients via activation of AMPK (Alcocer-Gomez et al., 2015). In support of this, there are low ATP levels and high mitochondrial reactive oxygen species in bone marrow cells, as well as high levels of IL-
$1 \beta$ and IL-18 in serum of fibromyalgia patients. Interestingly, all these biochemical alterations were restored to control values when bone marrow cells from patients with fibromyalgia are treated with metformin. Furthermore, this drug improves clinical symptoms (pain, fatigue, depression, disturbed sleep, and tender points) in these patients (Bullón et al., 2016). There is a need to explore the effects of metformin in patients with several types of chronic pain in order to validate the findings of preclinical studies.

\section{Anxiety and Depression}

Mounting evidence suggests the existence of a positive correlation between insulin resistance or diabetes and anxiety and depression (Rasgon and Kenna, 2005; Sharma and Fulton, 2013; Zemdegs et al., 2016; Zemdegs et al., 2019). For instance, the induction of insulin resistance or experimental diabetes in rodents through exposure to high-fat diet leads to symptoms of depression including anxiety, despair and anhedonia (Gariepy et al., 2010; Ho et al., 2012; André et al., 2014). Several studies also suggest that neuropathic pain is associated with stress, anxiety and depression (Yalcin et al., 2011; Descalzi et al., 2017; Hestehave et al., 2019; Humo et al., 2019; Murasawa et al., 2020) whereas that chronic stress exacerbates chronic pain (Narita et al., 2006; Li et al., 2017; Gruener et al., 2018; Sieberg et al., 2018). These comorbidities have considerably increased contributing to disability, sleep disturbances, poor quality of life and healthcare costs. Since metformin can reverse several experimental insulin resistance- or diabetes-, and neuropathic pain-induced changes, it is likely that this drug may diminish anxiety-like behavior in rodents and humans. Regarding insulin resistance and diabetes, metformin induces a rapid anxiolytic effect, activates AMPK, up-regulates FoxO3a protein and $\mathrm{GABA}_{\mathrm{A}}$ receptors expression and increases miniature inhibitory postsynaptic currents (Fan et al., 2018; Ji et al., 2019). Metformin also increases serotonin release in the ventral hippocampus, activity of serotonergic neurons in the dorsal raphe nucleus and promotes anxiolytic/antidepressantlike activities of mice fed a high-fat diet (Zemdegs et al., 2019). Likewise, metformin diminishes chronic stress-induced depression-like behaviors in mice (Fang et al., 2020). Authors suggest that this effect could be due to the activation of AMPK.

Regarding neuropathic pain, there is no studies showing the effect of metformin in nerve injury-induced anxiety/depression. Treatment with mirogabalin $(3-10 \mathrm{mg} / \mathrm{kg}$ ) relieves nerve injuryrelated anxiety-type behaviors and tactile allodynia (Murasawa et al., 2020), suggesting that reduction of neuropathic pain could lead to a reduction of the comorbidities. Pre-clinical studies have suggested that forced physical exercise decreases neuropathic pain in rodents (Kuphal et al., 2007; Chen et al., 2012; Groover et al., 2013; Guo et al., 2019). Exercise improves physical function and fibromyalgia symptoms (Schachter et al., 2003). As stated above, there are some studies suggesting that physical exercise reduces weight and pain by activation of AMPK in mice with neuropathic pain (King-Himmelreich et al., 2017; Slivicki et al., 2019). Since exercise reduces nociception in neuropathic rodents and humans, it is likely that this non-pharmacological intervention could also decrease nerve injury-induced anxiety- 
and depression-like behaviors in neuropathic patients. Considering that half of chronic pain patients have comorbid anxiety and depression (McWilliams et al., 2004), there is a necessity to develop pharmacological treatments which can reduce chronic pain and comorbidities. Thus, the possible therapeutic use of metformin could open a new avenue for the treatment of these comorbidities (Anderson et al., 2010; Erensoy et al., 2019). Whether metformin reduces comorbidities by reducing pain or other mechanisms is currently unknown.

\section{Cognitive Deficits}

There has been reported a link between neuropathic pain (including diabetic neuropathy) and cognitive deficits in rodents (Kodama et al., 2011; Shiers et al., 2018; Boccella et al., 2019; Liang et al., 2020; Won et al., 2020) and humans (Curatolo et al., 2017; Ojeda et al., 2018; Naranjo et al., 2019). However, current therapies for neuropathic pain have not considered this relationship. Recent pre-clinical studies show that cisplatin or paclitaxel induces neuropathic pain and deficits in spatial orientation and memory (cognitive impairment) in rodents and these effects are prevented by metformin. Moreover, this drug prevents tactile allodynia and restores chemotherapyinduced changes in white matter organization, neuronal arborization, and dendritic spine density (Zhou et al., 2016). In this sense, metformin abates pain-related cognitive impairment and restores functional and morphological changes in brain of neuropathic mice. In contrast, gabapentin is able to decrease pain, but not cognitive impairment (Shiers et al., 2018). Likewise, chronic treatment with metformin reduces nociception and cognitive dysfunction in high-fat diet-induced insulin resistance. This drug also decreases all metabolic changes induced by a high-fat diet in rodents (Pintana et al., 2012; Lennox et al., 2014; Muñoz-Arenas et al., 2020; Zhang et al., 2020). Interestingly, chronic treatment with metformin for 24 weeks improves cognitive performance, reduces depression and metabolic changes induces by type 2 diabetes in human beings (Guo et al., 2014; Ng et al., 2014). More basic and clinical studies are necessary to fully elucidate if metformin is effective to reduce chronic pain and cognitive deficits in neuropathic pain.

\section{PHARMACOKINETICS OF METFORMIN}

Metformin gastrointestinal absorption is apparently complete within 6 hours of ingestion (Scheen and Paquot, 2012). It is absorbed in the small intestine, particularly in jejunum and ileum. The intestinal absorption of metformin is mediated by the plasma membrane monoamine transporter (PMAT) expressed on the luminal side of enterocytes and organic cation transporter (OCT) 3 (OCT3, SLC22A3) expressed on the brush border of the enterocytes (Müller et al., 2005; Zhou et al., 2007; Graham et al., 2011). Once in the blood, the drug reaches the liver primarily by OCT1 (SLC22A1) and OCT3 (SLC22A3) expressed on the basolateral membrane of hepatocytes (Nies et al., 2009; Chen et al., 2010; Graham et al., 2011) in order to induce its anti-diabetic effects (Zhou et al.,
2001; Rena et al., 2017). Pharmacokinetic-pharmacodynamic modeling has shown a correlation between the time course of metformin concentrations in the portal vein and gut wall and hypoglycemic effect, instead of drug concentrations in liver (Stepensky et al., 2002; Sun et al., 2011). The time to reach maximal plasma concentrations in human beings after metformin administration $\left(\mathrm{T}_{\max }\right.$ ) is 1.5 to $2.7 \mathrm{~h}$ (Caillé et al., 1993; Sambol et al., 1996; Wei et al., 2009; Zhang et al., 2014; McCreight et al., 2018), which follows a multiphasic pattern (Graham et al., 2011), giving a peak plasma concentration $\left(\mathrm{C}_{\max }\right)$ of 1.1 to $2.5 \mu \mathrm{g} / \mathrm{ml}$ (Wei et al., 2009; Zhang et al., 2014; Dias et al., 2019), and a steady-state concentration range of 0.3 to $1.5 \mu \mathrm{g} / \mathrm{ml}$ (see Table 2). Plasma protein binding is negligible, and the drug is not metabolized (Scheen, 1996).

Once in blood, metformin enters the kidney cells through OCT1 and OCT2 expressed in the basolateral membrane (Kim et al., 2014). Metformin undergoes rapid and biphasic renal excretion (Melchior and Jaber, 1996). Renal excretion of this drug from the tubule cell to the lumen is mediated through multidrug and toxin extrusion protein 1 (MATE1, SLC47A1) and 2K (MATE2K, SLC47A2) expressed on the apical membrane of the renal proximal tubule cells (Sato et al., 2008; Tsuda et al., 2009; Ito et al., 2012). The elimination half-life $\left(t_{1 / 2}\right)$ is between 1.5 and $7 \mathrm{~h}$ (Tucker et al., 1981; Caillé et al., 1993), or longer if renal function is impaired (Caillé et al., 1993; Dias et al., 2019). Metformin is eliminated by glomerular filtration and tubular secretion. According to the clinical trials, the renal clearance of metformin is around $50 \mathrm{ml} / \mathrm{h}$ (Wei et al., 2009). Plasma concentrations of metformin decrease rapidly after intravenous administration (Graham et al., 2011). The clearance $(\mathrm{Cl} / \mathrm{F})$ range from 441 to $706 \mathrm{ml} / \mathrm{min}$ in healthy volunteers (Sirtori et al., 1978; Pentikäinen et al., 1979; Tucker et al., 1981; see Table 2).

Pharmacokinetic parameters can be modified after two different secondary doses of metformin (250 or $1000 \mathrm{mg}$ ). In this case, $\mathrm{C}_{\max }$ varied from $591.1 \pm 247.5$ to $1937.5 \pm 863.0 \mu \mathrm{g} /$ $\mathrm{ml}$ ), whereas $\mathrm{T}_{\max }$ and $\mathrm{t}_{1 / 2}$ did not show dose-dependent changes (Chung et al., 2018). A recent study showed that highintensity interval exercise diminishes metformin concentration $(2-3 \mathrm{~h})$, increases $\mathrm{C}_{\max }(4.4 \pm 2.5 \mu \mathrm{g} / \mathrm{ml})$ and diminishes $\mathrm{T}_{\max }$ $(2.7 \pm 0.9 \mathrm{~h})$ (Nikolaidis et al., 2020). Moreover, metformin pharmacokinetics is altered by severe renal impairment (Scheen, 1996), metformin intolerance (McCreight et al., 2018), but not by diabetes (Sambol et al., 1996; Markowicz-Piasecka et al., 2017; see Table 2).

\section{SIDE EFFECTS OF METFORMIN}

There is evidence that metformin treatment in human beings leads to gastrointestinal side effects including diarrhea, dyspepsia and flatulence in up to $30 \%$ of patients (Melchior and Jaber, 1996; Florez et al., 2010; Ji et al., 2015; Tanaka et al., 2015). Diarrhea has also been reported in rats with a dose of 200 to $250 \mathrm{mg} / \mathrm{kg} /$ day during 5 weeks (Acosta-Cota et al., 2019; Takemori et al., 2020). However, it not usual that pain studies report side effects. Thus, this is an important point to consider in future studies of pain. 
TABLE 2 | Pharmacokinetics of metformin in humans, horses and rats.

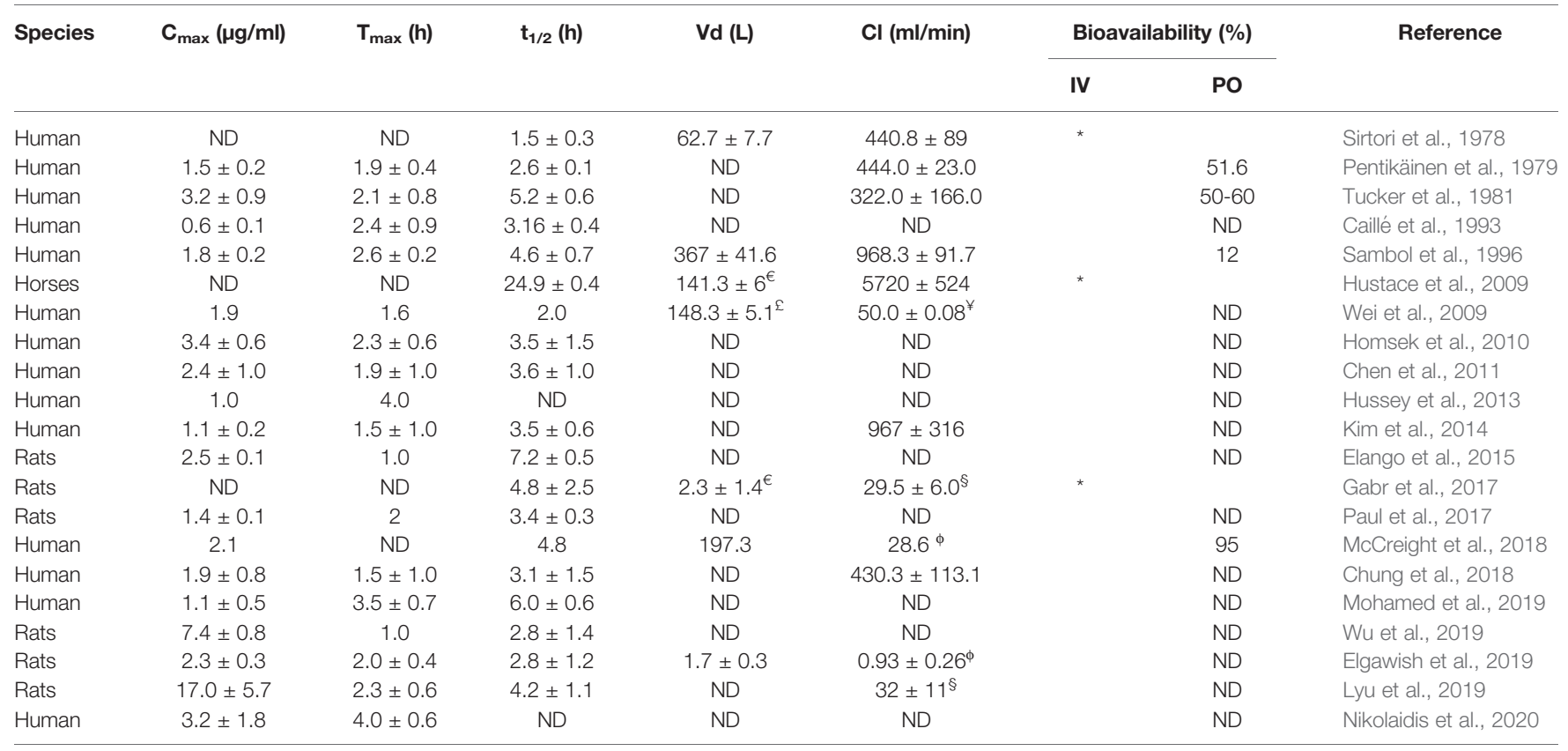

Data are the mean \pm standard error. ND, Not determined.

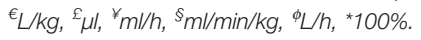

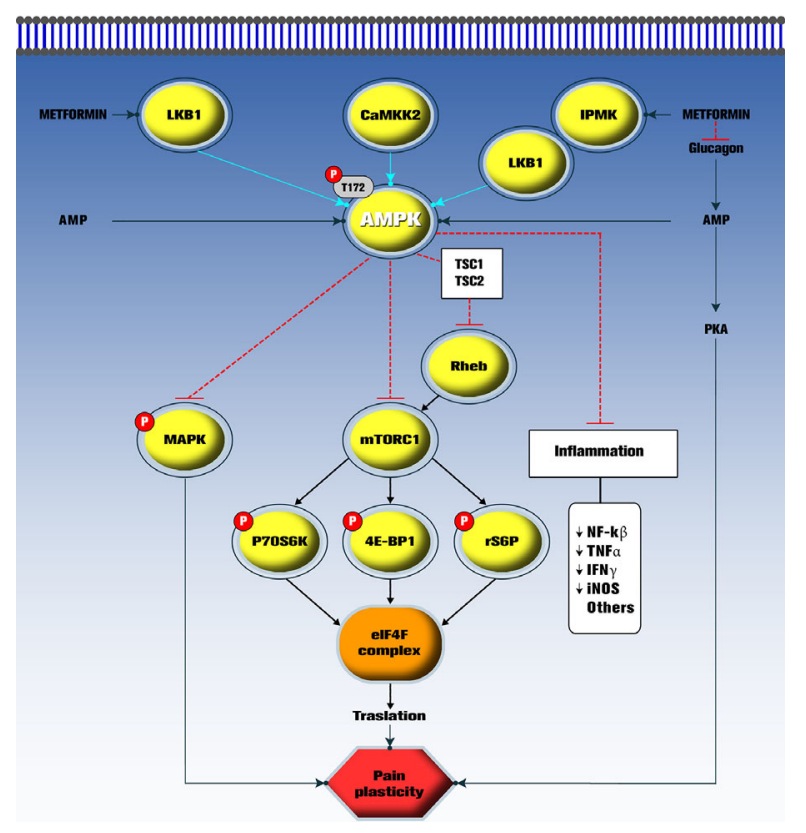

FIGURE 1 | Current mechanisms proposed for metformin in pathological pain. The mTOR/P70S6K/4E-BP1/rS6P pathway activates formation of the elF4F complex and promotes aberrant translation in nociceptors during pathological pain. Also, activation of mitogen-activated protein kinase (MAPK), inflammation and protein kinase A (PKA) pathways lead to pain plasticity. Metformin acts as a disease-modifying drug by indirectly activating AMPK. Once activated, phosphorylated AMPK inhibits the mTORC1 pathways reversing pain plasticity and pathological pain. Metformin also inhibits glucagon actions to induce its antihyperglycemic effect in diabetic conditions. However, the role of this pathway on pain has not been explored. LKB1, Liver kinase B1; CaMKK2, Calcium/calmodulin-dependent protein kinase kinase 2; IPMK, Inositol polyphosphate multikinase; AMPK, AMP-activated protein kinase; Rheb, GTP-bound Rheb GTPase; mTORC1, Mechanistic target of rapamycin complex 1; P70S6K, 70 kDa ribosomal protein S6 kinase; 4E-BP1, Eukaryotic translation initiation factor 4E (elF4E)-binding protein 1; rS6P, S6 ribosomal protein; elF4F: Eukaryotic translation initiation factor 4F; nNOS, Neuronal nitric oxide synthase; NF-k $\beta$ : Nuclear factor kappa $\beta$; TNF $\alpha$, Tumor necrosis factor $\alpha$; IFN $\gamma$, interferon- $\gamma$. 


\section{SYNOPSIS}

We have summarized the main pharmacological characteristics of metformin, a highly used drug in diabetic persons. This drug has been useful to treat people with pre-diabetes, metabolic syndrome and diabetes. Comprehensive data on pain indicate that metformin behave as a disease-modifying drug, as it targets a master switch kinase (AMPK) which in turn decreases the activity of mTORC1 and MAPK signaling in nociceptors and reduces pain in several models of pathological pain (Price and Dussor, 2013; Price et al., 2016; Asiedu et al., 2017; Figure 1). Moreover, metformin has pharmacological effects in rodent models of anxiety, depression and cognitive impairment. Interestingly, the mechanism of action of metformin has been unraveled in the last years. There is evidence to support that AMPK activation signaling underlies the effects of this drug in several pathologies including insulin resistance, diabetes and chronic neuropathic pain (Figure 1), although the role of AMPK in pain-related anxiety/depression and cognitive

\section{REFERENCES}

Acosta-Cota, S. J., Aguilar-Medina, E. M., Ramos-Payán, R., Rendón-Maldonado, J. G., Romero-Quintana, J. G., Montes-Avila, J., et al. (2019). Therapeutic effect of treatment with metformin and/or 4-hydroxychalcone in male Wistar rats with nonalcoholic fatty liver disease. Eur. J. Pharmacol. 863, 172699. doi: 10.1016/j.ejphar.2019.172699

Afshari, K., Dehdashtian, A., Haddadi, N. S., Haj-Mirzaian, A., Iranmehr, A., Ebrahimi, M. A., et al. (2018). Anti-inflammatory effects of metformin improve the neuropathic pain and locomotor activity in spinal cord injured rats: introduction of an alternative therapy. Spinal Cord 56 (11), 1032-1041. doi: 10.1038/s41393-018-0168-x

Alcocer-Gómez, E., Garrido-Maraver, J., Bullón, P., Marín-Aguilar, F., Cotán, D., Carrión, A. M., et al. (2015). Metformin and caloric restriction induce an AMPK-dependent restoration of mitochondrial dysfunction in fibroblasts from fibromyalgia patients. Biochem. Biophys. Acta 1852 (7), 1257-1267. doi: 10.1016/j.bbadis.2015.03.005

Anderson, R. J., Gott, B. M., Sayuk, G. S., Freedland, K. E., and Lustman, P. J. (2010). Antidepressant pharmacotherapy in adults with type 2 diabetes: rates and predictors of initial response. Diabetes Care 33 (3), 485-489. doi: 10.2337/ dc09-1466

Andre, C., Dinel, A. L., Ferreira, G., Laye, S., and Castanon, N. (2014). Dietinduced obesity progressively alters cognition, anxiety-like behavior and lipopolysaccharide-induced depressive-like behavior: focus on brain indoleamine 2, 3-dioxygenase activation. Brain Behav. Immun. 41, 10-21. doi: $10.1016 /$ j.bbi.2014.03.012

Asante, C. O., Wallace, V. C., and Dickenson, A. H. (2009). Formalin-induced behavioural hypersensitivity and neuronal hyperexcitability are mediated by rapid protein synthesis at the spinal level. Mol. Pain 5, 27. doi: 10.1186/17448069-5-27

Asiedu, M. N., Han, C., Dib-Hajj, S. D., Waxman, S. G., Price, T. J., and Dussor, G. (2017). The AMPK activator A769662 blocks voltage-gated sodium channels: discovery of a novel pharmacophore with potential utility for analgesic development. PloS One 12 (1), e0169882. doi: 10.1371/journal.pone.0169882

Augusto, P. S. A., Braga, A. V., Rodrigues, F. F., Morais, M. I., Dutra, M. M. G. B., Batista, C. R. A., et al (2019). Metformin antinociceptive effect in models of nociceptive and neuropathic pain is partially mediated by activation of opioidergic mechanisms. Eur. J. Pharmacol. 858, 172497. doi: 10.1016/ j.ejphar.2019.172497

Bang, S., Chen, Y., Ahima, R. S., and Kim, S. F. (2014). Convergence of IPMK and LKB1-AMPK signaling pathways on metformin action. Mol. Endocrinol. 28 (7), 1186-1193. doi: 10.1210/me.2014-1134 impairment is unknown. Also, it is unknown if metformin directly decreases comorbidities or it decreases pain and this reduction halts comorbidities. Of note, well-designed placebocontrolled clinical trials are needed to support the putative effect of metformin in preclinical studies, particularly in neuropathic pain and its comorbidities.

\section{AUTHOR CONTRIBUTIONS}

All authors contributed to the article and approved the submitted version.

\section{FUNDING}

This work was partially supported by Conacyt (grant CB-20172018/A1-S-40015 to VG-S).

Barragán-Iglesias, P., Oidor-Chan, V. H., Loeza-Alcocer, E., Pineda-Farias, J. B., Velazquez-Lagunas, I., Salinas-Abarca, A. B., et al. (2018). Evaluation of the neonatal streptozotocin model of diabetes in rats: Evidence for a model of neuropathic pain. Pharmacol. Rep. 70 (2), 294-303. doi: 10.1016/j.pharep.2017.09.002

Barragán-Iglesias, P., Kuhn, J., Vidal-Cantú, G. C., Salinas-Abarca, A. B., Granados-Soto, V., Dussor, G. O., et al. (2019). Activation of the integrated stress response in nociceptors drives methylglyoxal-induced pain. Pain 160 (1), 160-171. doi: 10.1097/j.pain.0000000000001387

Basbaum, A.II, Bautista, D. M., Scherrer, G., and Julius, D. (2009). Cellular and molecular mechanisms of pain. Cell 139 (2), 267-284. doi: 10.1016/ j.cell.2009.09.028

Bierhaus, A., Fleming, T., Stoyanov, S., Leffler, A., Babes, A., Neacsu, C., et al. (2012). Methylglyoxal modification of Nav1.8 facilitates nociceptive neuron firing and causes hyperalgesia in diabetic neuropathy. Nat. Med. 18 (6), 926. doi: $10.1038 / \mathrm{nm} .2750$

Boccella, S., Marabese, I., Iannotta, M., Belardo, C., Neugebauer, V., Mazzitelli, M., et al. (2019). Metabotropic glutamate receptor 5 and 8 modulate the ameliorative effect of ultramicronized palmitoylethanolamide on cognitive decline associated with neuropathic pain. Int. Mol. Sci. 20 (7), 1757. doi: 10.3390/ijms20071757

Boß, M., Newbatt, Y., Gupta, S., Collins, I., Brüne, B., and Namgaladze, D. (2016). AMPK-independent inhibition of human macrophage ER stress response by AICAR. Sci. Rep. 6, 32111. doi: 10.1038/srep32111

Bullón, P., Alcocer-Gómez, E., Carrión, A. M., Marín-Aguilar, F., GarridoMaraver, J., Román-Malo, L., et al. (2016). AMPK phosphorylation modulates pain by activation of NLRP3 inflammasome. Antioxid. Redox Signal. 24 (3), 157-170. doi: 10.1089/ars.2014.6120

Burton, M. D., Tillu, D. V., Mazhar, K., Mejia, G. L., Asiedu, M. N., Inyang, K., et al. (2017). Pharmacological activation of AMPK inhibits incision-evoked mechanical hypersensitivity and the development of hyperalgesic priming in mice. Neuroscience 359, 119-129. doi: 10.1016/j.neuroscience.2017.07.020

Byrne, F. M., Cheetham, S., Vickers, S., and Chapman, V. (2015). Characterisation of pain responses in the high fat diet/streptozotocin model of diabetes and the analgesic effects of antidiabetic treatments. J. Diabetes Res. 2015, 752481. doi: $10.1155 / 2015 / 752481$

Caillé, G., Lacasse, Y., Raymond, M., Landriault, H., Perrotta, M. G., Picirilli, G., et al. (1993). Bioavailability of metformin in tablet form using a new highpressure liquid chromatography assay method. Biopharm. Drug Dispos. 14 (3), 257-263. doi: 10.1002/bdd.2510140308

Campbell, I. W., and Howlett, H. C. (1995). Worldwide experience of metformin as an effective glucose-lowering agent: a meta-analysis. Diabetes/Metabol. Rev. 11 (S1), S57-S62. doi: 10.1002/dmr.5610110509 
Chen, L., Zhou, Z., Shen, M., and Ma, A. (2011). Simultaneous determination and pharmacokinetic study of metformin and rosiglitazone in human plasma by HPLC-ESI-MS. J. Chromatogr. Sci. 49 (2), 94-100. doi: 10.1093/chrsci/49.2.94

Chen, L., Pawlikowski, B., Schlessinger, A., More, S. S., Stryke, D., Johns, S. J., et al. (2010). Role of organic cation transporter 3 (SLC22A3) and its missense variants in the pharmacologic action of metformin. Pharmacogenet. Genomics 20 (11), 687-699. doi: 10.1097/FPC.0b013e32833fe789

Chen, Y. W., Li, Y. T., Chen, Y. C., Li, Z. Y., and Hung, C. H. (2012). Exercise training attenuates neuropathic pain and cytokine expression after chronic constriction injury of rat sciatic nerve. Anesth. Analg. 114 (6), 1330-1337. doi: 10.1213/ANE.0b013e31824c4ed4

Chung, H., Oh, J., Yoon, S. H., Yu, K. S., Cho, J. Y., and Chung, J. Y. (2018). A non-linear pharmacokinetic-pharmacodynamic relationship of metformin in healthy volunteers: an open-label, parallel group, randomized clinical study. PloS One 13 (1), e0191258-e0191258. doi: 10.1371/journal.pone. 0191258

Clarke, B. F., and Campbell, I. W. (1977). Comparison of metformin and chlorpropamide in non-obese, maturity-onset diabetics uncontrolled by diet. Br. Med. J. 2 (6102), 1576-1578. doi: 10.1136/bmj.2.6102.1576

Clarke, B. F., and Duncan, L. J. (1968). Comparison of chlorpropamide and metformin treatment on weight and blood-glucose response of uncontrolled obese diabetics. Lancet 291 (7534), 123-126. doi: 10.1016/s0140-6736(68) 92726-8

Coccurello, R., Nazio, F., Rossi, C., De Angelis, F., Vacca, V., Giacovazzo, G., et al. (2018). Effects of caloric restriction on neuropathic pain, peripheral nerve degeneration and inflammation in normometabolic and autophagy defective prediabetic Ambral mice. PloS One 13 (12), e0208596. doi: 10.1371/ journal.pone.0208596

Codeluppi, S., Svensson, C.II, Hefferan, M. P., Valencia, F., Silldorff, M. D., Oshiro, M., et al. (2009). The Rheb-mTOR pathway is upregulated in reactive astrocytes of the injured spinal cord. J. Neurosci. 29 (4), 1093-1104. doi: 10.1523/JNEUROSCI.4103-08.2009

Cooper, M. A., Kluding, P. M., and Wright, D. E. (2016). Emerging relationships between exercise, sensory nerves, and neuropathic pain. Front. Neurosci. 10:372:372. doi: 10.3389/fnins.2016.00372

Cooper, M. A., O’Meara, B., Jack, M. M., Elliot, D., Lamb, B., Khan, Z. W., et al. (2018). Intrinsic activity of C57BL/6 substrains associates with high-fat dietinduced mechanical sensitivity in mice. J. Pain 19 (11), 1285-1295. doi: 10.1016/j.jpain.2018.05.005

Crook, R. J., Dickson, K., Hanlon, R. T., and Walters, E. T. (2014). Nociceptive sensitization reduces predation risk. Curr. Biol. 24 (10), 1121-1125. doi: 10.1016/ j.cub.2014.03.043

Curatolo, M., La, G. B., Cosentino, G., Baschi, R., Salemi, G., Talotta, R., et al. (2017). Motor cortex tRNS improves pain, affective and cognitive impairment in patients with fibromyalgia: preliminary results of a randomised shamcontrolled trial. Clin. Exp. Rheumatol. 35 (3), 100-105.

Das, V., Kroin, J. S., Moric, M., McCarthy, R. J., and Buvanendran, A. (2020). Early treatment with metformin in a mice model of complex regional pain syndrome reduces pain and edema. Anesth. Anal. 130 (2), 525-534. doi: 10.1213/ ANE.0000000000004057

Dasgupta, B., and Milbrandt, J. (2007). Resveratrol stimulates AMP kinase activity in neurons. Proc. Natl. Acad. Sci. U.S.A. 104 (17), 7217-7222. doi: 10.1073/ pnas.0610068104

DeFronzo, R. A., and Goodman, A. M. (1995). Efficacy of metformin in patients with non-insulin-dependent diabetes mellitus. N. Engl. J. Med. 333 (9), 541549. doi: 10.1056/NEJM199508313330902

Descalzi, G., Mitsi, V., Purushothaman, I., Gaspari, S., Avrampou, K., Loh, Y. E., et al. (2017). Neuropathic pain promotes adaptive changes in gene expression in brain networks involved in stress and depression. Sci. Signal. 10 (471), eaaj1549. doi: 10.1126/scisignal.aaj1549

Dias, B. C. L., Fachi, M. M., de Campos, M. L., Degaut, F. L., Peccinini, R. G., and Pontarolo, R. (2019). A new HPLC-MS/MS method for the simultaneous quantification of SGLT2 inhibitors and metformin in plasma and its application to a pharmacokinetic study in healthy volunteers. Biomed. Chromatogr. 33 (11), e4663. doi: 10.1002/bmc.4663

Dong, Y., Zhang, M., Wang, S., Liang, B., Zhao, Z., Liu, C., et al. (2010). Activation of AMP-activated protein kinase inhibits oxidized LDL-triggered endoplasmic reticulum stress in vivo. Diabetes 59 (6), 1386-1396. doi: 10.2337/db09-1637
Dowling, R. J., Zakikhani, M., Fantus, I. G., Pollak, M., and Sonenberg, N. (2007). Metformin inhibits mammalian target of rapamycin-dependent translation initiation in breast cancer cells. Cancer Res. 67 (22), 10804-10812. doi: 10.1158/ 0008-5472.CAN-07-2310

Dunn, C. J., and Peters, D. H. (1995). Metformin. Drugs 49, 721-749. doi: 10.2165/ 00003495-199549050-00007

Elango, H., Ponnusankar, S., and Sankar Sundaram, S. (2015). Assessment of pharmacodynamic and pharmacokinetic interaction of aqueous extract of Cassia auriculata L. and metformin in rats. Pharmacogn. Mag. 11 (Suppl 3), S423-S426. doi: 10.4103/0973-1296.168986

Elgawish, M. S., Nasser, S., Salama, I., Abbas, A. M., and Mostafa, S. M. (2019). Liquid chromatography tandem mass spectrometry for the simultaneous determination of metformin and pioglitazone in rat plasma: Application to pharmacokinetic and drug-drug interaction studies. J. Chromatogr. B Analyt. Technol. Biomed. Life Sci. 1124, 47-57. doi: 10.1016/j.jchromb. 2019.05.036

Erensoy, H., Niafar, M., Ghafarzadeh, S., Aghamohammadzadeh, N., and Nader, N. D. (2019). A pilot trial of metformin for insulin resistance and mood disturbances in adolescent and adult women with polycystic ovary syndrome. Gynecol. Endocrinol. 35 (1), 72-75. doi: 10.1080/09513590.2018.1498476

Falcão-Pereira, A., Silva-Pereira, L. M., Pereira-Silva, C. M., Freitas-Alves, B. W., Sales-Barbosa, J., Pinto, F. M. M., et al. (2019). Metformin reduces c-Fos and ATF3 expression in the dorsal root ganglia and protects against oxaliplatininduced peripheral sensory neuropathy in mice. Neurosci. Lett. 709:134378. doi: 10.1016/j.neulet.2019.134378

Fan, J., Li, D., Chen, H. S., Huang, J. G., Xu, J. F., Zhu, W. W., et al. (2018). Metformin produces anxiolytic-like effects in rats by facilitating $\mathrm{GABA}_{\mathrm{A}}$ receptor trafficking to membrane. Br. J. Pharmacol. 176 (2), 297-316. doi: 10.1111/bph.14519

Fang, W., Zhang, J., Hong, L., Huang, W., Dai, X., Ye, Q., et al. (2020). Metformin ameliorates stress-induced depression-like behaviors via enhancing the expression of BDNF by activating AMPK/CREB-mediated histone acetylation. J. Affect. Disord. 260, 302-313. doi: 10.1016/j.jad.2019.09.013

Fayaz, A., Croft, P., Langford, R. M., Donaldson, L. J., and Jones, G. T. (2016). Prevalence of chronic pain in the UK: a systematic review and meta-analysis of population studies. BMJ Open 6 (6), e010364. doi: 10.1136/bmjopen-2015010364

Finnerup, N. B., Sindrup, S. H., and Jensen, T. S. (2010). Recent advances in pharmacological treatment of neuropathic pain. F1000 Med. Rep. 2:52. doi: 10.3410/M2-52

Finnerup, N. B., Attal, N., Haroutounian, S., McNicol, E., Baron, R., Dworkin, R. H., et al. (2015). Pharmacotherapy for neuropathic pain in adults: a systematic review and meta-analysis. Lancet Neurol. 14 (2), 162-173. doi: 10.1016/S14744422(14)70251-0

Fischer, Y., Thomas, J., Rösen, P., and Kammermeier, H. (1995). Action of metformin on glucose transport and glucose transporter GLUT1 and GLUT4 in heart muscle cells from healthy and diabetic rats. Endocrinology 136 (2), 412-420. doi: 10.1210/endo.136.2.7835271

Florez, H., Luo, J., Castillo-Florez, S., Mitsi, G., Hanna, J., Tamariz, L., et al. (2010). Impact of metformin-induced gastrointestinal symptoms on quality of life and adherence in patients with type 2 diabetes. Postgrad. Med. 122 (2), 112-120. doi: 10.3810/pgm.2010.03.2128

Fogarty, S., Ross, F. A., Ciruelos, D. V., Gray, A., Gowans, G. J., and Hardie, D. J. (2016). AMPK causes cell cycle arrest in LKB1-deficient cells via activation of CAMKK2. Mol. Cancer Res. 14 (8), 683-695. doi: 10.1158/1541-7786.MCR15-0479

Foretz, M., Hébrard, S., Leclerc, J., Zarrinpasherneh, E., Soty, M., Mithieux, G., et al. (2010). Metformin inhibits hepatic gluconeogenesis in mice independently of the LKB1/AMPK pathway via a decrease in hepatic energy state. J. Clin. Invest. 120 (7), 2355-2369. doi: 10.1172/JCI40671

Gabr, R. Q., El-Sherbeni, A. A., Ben-Eltriki, M., El-Kadi, A. O., and Brocks, D. R. (2017). Pharmacokinetics of metformin in the rat: assessment of the effect of hyperlipidemia and evidence for its metabolism to guanylurea. Can. J. Physiol. Pharmacol. 95 (5), 530-538. doi: 10.1139/cjpp-2016-0329

Galuska, D., Nolte, L. A., Zierath, J. R., and Wallberg-Henriksson, H. (1994). Effect of metformin on insulin-stimulated glucose transport in isolated skeletal muscle obtained from patients with NIDDM. Diabetologia 37 (8), 826-832. doi: $10.1007 /$ bf00404340 
Garber, A. J. (1997). Metformin: mechanisms of antihyperglycemic action, other pharmacodynamic properties, and safety perspectives. Endocr. Pract. 3 (6), 359-370. doi: 10.4158/EP.3.6.359

García, G., Gutiérrez-Lara, E. J., Centurión, D., Granados-Soto, V., and Murbartián, J. (2019). Fructose-induced insulin resistance as a model of neuropathic pain in rats. Neuroscience 404, 233-245. doi: 10.1016/j.neuroscience. 2019.01.063

Gariepy, G., Nitka, D., and Schmitz, N. (2010). The association between obesity and anxiety disorders in the population: a systematic review and meta-analysis. Int. J. Obes. (Lond) 34 (3), 407-419. doi: 10.1038/ijo.2009.252

Gawler, D. J., Wilson, A., and Houslay, M. D. (1989). Metformin treatment of lean and obese Zucker rats modulates the ability of glucagon and insulin to regulate hepatocyte adenylate cyclase activity. J. Endocrinol. 122 (1), 207-212. doi: $10.1677 /$ joe. 0.1220207

Ge, A., Wang, S., Miao, B., and Yan, M. (2018). Effects of metformin on the expression of AMPK and STAT3 in the spinal dorsal horn of rats with neuropathic pain. Mol. Med. Rep. 17 (4), 5229-5237. doi: 10.3892/mmr. 2018.8541

Géranton, S. M., Jiménez-Díaz, L., Torsney, C., Tochiki, K. K., Stuart, S. A., Leith, J. L., et al. (2009). A rapamycin-sensitive signaling pathway is essential for the full expression of persistent pain states. J. Neurosci. 29 (47), 15017-15027. doi: 10.1523/JNEUROSCI.3451-09.2009

Graham, G. G., Punt, J., Arora, M., Day, R., Doogue, M. P., Duong, J. K., et al. (2011). Clinical pharmacokinetics of metformin. Clin. Pharmacokinet. 50 (2), 81-98. doi: 10.2165/11534750-000000000-00000

Green, M. F., Scott, J. W., Steel, R., Oakhill, J. S., Kemp, B. E., and Means, A. R. (2011). $\mathrm{Ca}^{2+} /$ Calmodulin-dependent protein kinase kinase beta is regulated by multisite phosphorylation. J. Biol. Chem. 286 (32), 28066-28079. doi: 10.1074/ jbc.M111.251504

Groover, A. L., Ryals, J. M., Guilford, B. L., Wilson, N. M., Christianson, J. A., and Wright, D. E. (2013). Exercise-mediated improvements in painful neuropathy associated with prediabetes in mice. Pain 154 (12), 2658-2667. doi: 10.1016/ j.pain.2013.07.052

Gruener, H., Zeilig, G., Laufer, Y., Blumen, N., and Defrin, R. (2018). Increased psychological distress among individuals with spinal cord injury is associated with central neuropathic pain rather than the injury characteristics. Spinal Cord 56 (2), 176-184. doi: 10.1038/s41393-017-0014-6

Guilford, B. L., Ryals, J. M., and Wright, D. E. (2011). Phenotypic changes in diabetic neuropathy induced by a high-fat diet in diabetic C57BL/6 mice. Exp. Diabetes Res. 2011:848307. doi: 10.1155/2011/848307

Guo, M., Mi, J., Jiang, Q. M., Xu, J. M., Tang, Y. Y., Tian, G., et al. (2014). Metformin may produce antidepressant effects through improvement of cognitive function among depressed patients with diabetes mellitus. Clin. Exp. Pharmacol. Physiol. 41 (9), 650-656. doi: 10.1111/1440-1681.12265

Guo, J. B., Chen, B. L., Wang, Y., Zhu, Y., Song, G., Yang, Z., et al. (2019). Metaanalysis of the effect of exercise on neuropathic pain induced by peripheral nerve injury in rat models. Front. Neurol. 10, 636. doi: 10.3389/fneur. 2019.00636

Hardie, D. G., Carling, D., and Carlson, M. (1998). The AMP-activated/SNF1 protein kinase subfamily: metabolic sensors of the eukaryotic cell? Annu. Rev. Biochem. 67, 821-855. doi: 10.1146/annurev.biochem.67.1.821

Hasanvand, A., Amini-Khoei, H., Hadian, M. R., Abdollahi, A., Tavangar, S. M., Tavangar, S. M., et al. (2016). Anti-inflammatory effect of AMPK signaling pathway in rat model of diabetic neuropathy. Inflammopharmacology 24 (5), 207-219. doi: 10.1007/s10787-016-0275-2

Hawley, S. A., Boudeau, J., Reid, J. L., Mustard, K. J., Udd, L., Mäkelä, T. P., et al. (2003). Complexes between the LKB1 tumor suppressor, STRAD alpha/beta and MO25 alpha/beta are upstream kinases in the AMP-activated protein kinase cascade. J. Biol. 2 (4):28. doi: 10.1186/1475-4924-2-28

Hay, N., and Sonenberg, N. (2004). Upstream and downstream of mTOR. Genes Dev. 18 (16), 1926-1945. doi: 10.1101/gad.1212704

Hermann, L. S. (1979). Metformin: a review of its pharmacological properties and therapeutic use. Diabetes Metab. 5 (3), 233-245.

Hestehave, S., Abelson, K. S., Pedersen, T. B., and Munro, G. (2019). Stress sensitivity and cutaneous sensory thresholds before and after neuropathic injury in various inbred and outbred rat strains. Behav. Brain Res. 375, 112149. doi: 10.1016/j.bbr.2019.11214
Ho, L., Varghese, M., Wang, J., Zhao, W., Chen, F., Knable, L. A., et al. (2012). Dietary supplementation with decaffeinated green coffee improves dietinduced insulin resistance and brain energy metabolism in mice. Nutt. Neurosci. 15 (1), 37-45. doi: 10.1179/1476830511Y.0000000027

Homsek, I., Parojcić, J., Dacević, M., Petrović, L., and Dusan Jovanović, D. (2010). Justification of metformin hydrochloride biowaiver criteria based on bioequivalence study. Arzneimittelforschung 60 (9), 553-559. doi: 10.1055/s0031-1296324

Howlett, H. C., and Bailey, C. J. (1999). A risk-benefit assessment of metformin in type 2 diabetes mellitus. Drug Saf. 20 (6), 489-503. doi: 10.2165/00002018199920060-00003

Huang, Q., Chen, Y., Gong, N., and Wang, Y. X. (2016). Methylglyoxal mediates streptozotocin-induced diabetic neuropathic pain via activation of the peripheral TRPA1 and Nav1.8 channels. Metabolism 65 (4), 463-474. doi: 10.1016/j.metabol.2015.12.002

Humo, M., Lu, H., and Yalcin, I. (2019). The molecular neurobiology of chronic pain-induced depression. Cell Tissue Res. 377 (1), 21-43. doi: 10.1007/s00441019-03003-z

Hundal, H. S., Ahmed, A., Gumà, A., Mitsumoto, Y., Marette, A., Rennie, M. J., et al. (1992). Biochemical and immunocytochemical localization of the 'GLUT5 glucose transporter' in human skeletal muscle. Biochem. J. 286 (Pt 2), 339-343. doi: $10.1042 /$ bj2860339

Hundal, R. S., Krssak, M., Dufour, S., Laurent, D., Lebon, V., Chandramouli, V., et al. (2000). Mechanism by which metformin reduces glucose production in type 2 diabetes. Diabetes 49 (12), 2063-2069. doi: 10.2337/diabetes.49.12.2063

Hussey, E. K., Kapur, A., O'Connor-Semmes, R., Tao, W., Rafferty, B., Polli, J. W., et al. (2013). Safety, pharmacokinetics and pharmacodynamics of remogliflozin etabonate, a novel SGLT2 inhibitor, and metformin when co-administered in subjects with type 2 diabetes mellitus. BMC Pharmacol. Toxicol. 14, 25. doi: 10.1186/2050-6511-14-25

Hustace, J. L., Firshman, A. M., and Mata, J. E. (2009). Pharmacokinetics and bioavailability of metformin in horses. Am. J. Vet. Res. 70 (5), 665-668. doi: 10.2460/ajvr.70.5.665

Inyang, K. E., McDougal, T. A., Ramirez, E. D., Williams, M., Laumet, G., Kavelaars, A., et al. (2019). Alleviation of paclitaxel-induced mechanical hypersensitivity and hyperalgesic priming with AMPK activators in male and female mice. Neurobiol. Pain 6, 100037. doi: 10.1016/j.ynpai.2019.100037

Ito, S., Kusuhara, H., Yokochi, M., Toyoshima, J., Inoue, K., Yuasa, H., et al. (2012). Competitive inhibition of the luminal efflux by multidrug and toxin extrusions, but not basolateral uptake by organic cation transporter 2, is the likely mechanism underlying the pharmacokinetic drug-drug interactions caused by cimetidine in the kidney. J. Pharmacol. Exp. Ther. 340 (2), 393-403. doi: 10.1124/jpet.111.184986

Jack, M. M., Ryals, J. M., and Wright, D. E. (2012). Protection from diabetesinduced peripheral sensory neuropathy-a role for elevated glyoxalase I? Exp. Neurol. 234 (1), 62-69. doi: 10.1016/j.expneurol.2011.12.015

Jensen, T. S., Baron, R., Haanpää, M., Kalso, E., Loeser, J. D., Rice, A. S., et al. (2011). A new definition of neuropathic pain. Pain 152 (10), 2204-2205. doi: 10.1016/j.pain.2011.06.017

Ji, R. R., Gereau, R. W., Malcangio, M., and Strichartz, G. R. (2009). MAP kinase and pain. Brain Res. Rev. 60 (1), 135-148. doi: 10.1016/j.brainresrev.2008.12.011

Ji, R. R., Berta, T., and Nedergaard, M. (2013). Glia and pain: is chronic pain a gliopathy? Pain 154 Suppl 1 (0 1), S10-S28. doi: 10.1016/j.pain.2013.06.022

Ji, L., Zinman, B., Patel, S., Ji, J., Bailes, Z., Sandra Thiemann, S., et al. (2015). Efficacy and safety of linagliptin co-administered with low-dose metformin once daily versus high-dose metformin twice daily in treatment-naïve patients with type 2 diabetes: a double-blind randomized trial. Randomized Controlled Trial Adv. Ther. 32 (3), 201-215. doi: 10.1007/s12325-015-0195-3

Ji, S., Wang, L., and Li, L. (2019). Effect of metformin on short-term high-fat dietinduced weight gain and anxiety-like behavior and the gut microbiota. Front. Endocrinol. 10, 704. doi: 10.3389/fendo.2019.00704

Jiménez-Díaz, L., Géranton, S. M., Passmore, G. M., Leith, J. L., Fisher, A. S., Berliocchi, L., et al. (2008). Local translation in primary afferent fibers regulates nociception. PloS One 3 (4), e1961. doi: 10.1371/journal.pone.0001961

Johansen, A., Romundstad, L., Nielsen, C. S., Schirmer, H., and Stubhaug, A. (2012). Persistent postsurgical pain in a general population: prevalence and predictors in the Tromsø study. Pain 153 (7), 1390-1396. doi: 10.1016/ j.pain.2012.02.018 
Johansen, K. (1999). Efficacy of metformin in the treatment of NIDDM. Metaanalysis. Diabetes Care 22 (1), 33-37. doi: 10.2337/diacare.22.1.33

Kemp, B. E., Mitchelhill, K.II, Stapleton, D., Michell, B. J., Chen, Z. P., and Witters, L. A. (1999). Dealing with energy demand: the AMP-activated protein kinase. Trends Biochem. Sci. 24 (1), 22-25. doi: 10.1016/s0968-0004(98)01340-1

Khoutorsky, A., and Price, T. J. (2018). Translational control mechanisms in persistent pain. Trends Neurosci. 41 (2), 100-114. doi: 10.1016/j.tins. 2017.11.006

Kim, S. J., Thomas, K. S., Calejesan, A. A., and Zhuo, M. (1998). Macromolecular synthesis contributes to nociceptive response to subcutaneous formalin injection in mice. Neuropharmacology 37 (8), 1091-1093. doi: 10.1016/ s0028-3908(98)00099-9

Kim, A., Chung, I., Yoon, S. H., Yu, K. S., Lim, K. S., Cho, J. Y., et al. (2014). Effects of proton pump inhibitors on metformin pharmacokinetics and pharmacodynamics. Drug Metabol. Dispos. 42 (7), 1174-1179. doi: 10.1124/ dmd.113.055616

Kimura, N., Tokunaga, C., Dalal, S., Richardson, C., Yoshino, K.II, Hara, K., et al. (2003). A possible linkage between AMP-activated protein kinase (AMPK) and mammalian target of rapamycin (mTOR) signalling pathway. Genes Cells 8 (1), 65-79. doi: 10.1046/j.1365-2443.2003.00615.x

King-Himmelreich, T. S., Möser, C. V., Wolters, M. C., Schmetzer, J., Schreiber, Y., Ferreirós, N., et al. (2017). AMPK contributes to aerobic exercise-induced antinociception downstream of endocannabinoids. Neuropharmacology 124, 134-142. doi: 10.1016/j.neuropharm.2017.05.002

Klann, E., and Dever, T. E. (2004). Biochemical mechanisms for translational regulation in synaptic plasticity. Nat. Rev. Neurosci. 5 (12), 931-942. doi: 10.1038/nrn1557

Kodama, D., Ono, H., and Tanabe, M. (2011). Increased hippocampal glycine uptake and cognitive dysfunction after peripheral nerve injury. Pain 152 (4), 809-817. doi: 10.1016/j.pain.2010.12.029

Kuphal, K. E., Fibuch, E. E., and Taylor, B. K. (2007). Extended swimming exercise reduces inflammatory and peripheral neuropathic pain in rodents. J. Pain 8 (12), 989-997. doi: 10.1016/j.jpain.2007.08.001

Lee, J. Y., Choi, H. Y., and Yune, T. Y. (2015). MMP-3 secreted from endothelial cells of blood vessels after spinal cord injury activates microglia, leading to oligodendrocyte cell death. Neurobiol. Dis. 82, 141-151. doi: 10.1016/ j.nbd.2015.06.002

Lennox, R., Porter, D. W., Flatt, P. R., Holscher, C., Irwin, N., and Gault, V. A. (2014). Comparison of the independent and combined effects of sub-chronic therapy with metformin and a stable GLP-1 receptor agonist on cognitive function, hippocampal synaptic plasticity and metabolic control in high-fat fed mice. Neuropharmacology 86, 22-30. doi: 10.1016/j.neuropharm.2014.06.026

Li, M. J., Liu, L. Y., Chen, L., Cai, J., and Wan, Y. (2017). Chronic stress exacerbates neuropathic pain via the integration of stress-affect-related information with nociceptive information in the central nucleus of the amygdala. Pain 158 (4), 717-739. doi: 10.1097/j.pain.0000000000000827

Liang, J., Yang, Q., Zhu, M. J., Jin, Y., and Du, M. (2013). AMP-activated protein kinase (AMPK) $\alpha_{2}$ subunit mediates glycolysis in postmortem skeletal muscle. Meat Sci. 95 (3), 536-541. doi: 10.1016/j.meatsci.2013.05.025

Liang, L., Wei, J., Tian, L., Nagendra, B. V. P., Gao, F., Zhang, J., et al. (2020). Paclitaxel induces sex-biased behavioral deficits and changes in gene expression in mouse prefrontal cortex. Neuroscience 426, 168-178. doi: 10.1016/j.neuroscience. 2019.11.031

Lin, H. Z., Yang, S. Q., Chuckaree, C., Kuhajda, F., Ronnet, G., and Diehl, A. M. (2000). Metformin reverses fatty liver disease in obese, leptin-deficient mice. Nat. Med. 6 (9), 998-1003. doi: 10.1038/79697

Lin, J. Y., He, Y. N., Zhu, N., and Peng, B. (2018). Metformin attenuates increase of synaptic number in the rat spinal dorsal horn with painful diabetic neuropathy induced by type 2 diabetes: a stereological study. Neurochem. Res. 43 (12), 2232-2239. doi: 10.1007/s11064-018-2642-4

Lister, K. C., Bouchard, S. M., Markova, T., Aternali, A., Denecli, P., Pimentel, S. D., et al. (2020). Chronic pain produces hypervigilance to predator odor in mice. Curr. Biol. 30 (15), R866-R867. doi: 10.1016/j.cub.2020.06.025

Liu, Y., Li, J., Li, H., Shang, Y., Guo, Y., Li, Z., et al. (2019). AMP-Activated protein kinase activation in dorsal root ganglion suppresses $\mathrm{mTOR} / \mathrm{p} 70 \mathrm{~S} 6 \mathrm{~K}$ signaling and alleviates painful radiculopathies in lumbar disc herniation rat model. Spine 44 (15), E865-E872. doi: 10.1097/BRS.0000000000003005

Ludman, T., and Melemedjian, O. K. (2019). Bortezomib and metformin opposingly regulate the expression of hypoxia-inducible factor alpha and the consequent development of chemotherapy-induced painful peripheral neuropathy. Mol. Pain 15:1744806919850043. doi: 10.1177/1744806919850043

Luo, C., Kuner, T., and Kuner, R. (2014). Synaptic plasticity in pathological pain. Trends Neurosci. 37 (6), 343-355. doi: 10.1016/j.tins.2014.04.002

Luo, T., Nocon, A., Fry, J., Sherban, A., Rui, X., Jiang, B., et al. (2016). AMPK activation by metformin suppresses abnormal extracellular matrix remodeling in adipose tissue and ameliorates insulin resistance in obesity. Diabetes 65 (8), 2295-2310. doi: 10.2337/db15-1122

Lupachyk, S., Watcho, P., Obrosov, A. A., Stavniichuk, R., and Obrosova, I. G. (2013). Endoplasmic reticulum stress contributes to prediabetic peripheral neuropathy. Exp. Neurol. 247, 342-348. doi: 10.1016/j.expneurol.2012.11.001

Lyu, Y., Zhang, Y., Yang, M., Lin, L., Yang, X., Cheung, S. C. K., et al. (2019). Pharmacokinetic interactions between metformin and berberine in rats: Role of oral administration sequences and microbiota. Life Sci. 235:116818. doi: 10.1016/j.lfs.2019.116818

Ma, J., Yu, H., Liu, J., Chen, Y., Wang, Q., and Xiang, L. (2015). Metformin attenuates hyperalgesia and allodynia in rats with painful diabetic neuropathy induced by streptozotocin. Eur. J. Pharmacol. 764, 599-606. doi: 10.1016/ j.ejphar.2015.06.010

Manion, J., Waller, M. A., Clark, T., Massingham, J. N., and Neely, G. G. (2019). Developing modern pain therapies. Front. Neurosci. 13, 1370. doi: 10.3389/ fnins.2019.01370

Mao-Ying, Q. L., Kavelaars, A., Krukowski, K., Huo, X. J., Zhou, W., Price, T. J., et al. (2014). The anti-diabetic drug metformin protects against chemotherapyinduced peripheral neuropathy in a mouse model. PloS One 9 (6), e100701. doi: 10.1371/journal.pone.0100701

Markowicz-Piasecka, M., Huttunen, K. M., Mateusiak, L., Mikiciuk-Olasik, E., and Sikora, J. (2017). Is metformin a perfect drug? Updates in pharmacokinetics and pharmacodynamics. Curr. Pharm. Des. 23 (17), 2532-2550. doi: 10.2174/ 1381612822666161201152941

Maruthur, N. M., Tseng, E., Hutfless, S., Wilson, L. M., Suarez-Cuervo, C., Berger, Z., et al. (2016). Diabetes medications as monotherapy or metformin-based combination therapy for type 2 diabetes: a systematic review and metaanalysis. Ann. Intern. Med. 164 (11), 740-751. doi: 10.7326/M15-2650

McCreight, L. J., Stage, T. B., Connelly, P., Lonergan, M., Nielsen, F., Prehn, C., et al. (2018). Pharmacokinetics of metformin in patients with gastrointestinal intolerance. Diabetes Obes. Metab. 20 (7), 1593-1601. doi: 10.1111/dom.13264

McWilliams, L. A., Goodwin, R. D., and Cox, B. J. (2004). Depression and anxiety associated with three pain conditions: results from a nationally representative sample. Pain 111 (1-2), 77-83. doi: 10.1016/j.pain.2004.06.002

Megat, S., and Price, T. J. (2018). Therapeutic opportunities for pain medicines via targeting of specific translation signaling mechanisms. Neurobiol. Pain. 4, 819. doi: 10.1016/j.ynpai.2018.02.001

Mejia, G. L., Asiedu, M. N., Hitoshi, Y., Dussor, G., and Price, T. J. (2016). The potent, indirect adenosine monophosphate-activated protein kinase activator R419 attenuates mitogen-activated protein kinase signaling, inhibits nociceptor excitability, and reduces pain hypersensitivity in mice. Pain Rep. 1 (1), e562. doi: 10.1097/PR9.0000000000000562

Melchior, W. R., and Jaber, L. A. (1996). Metformin: An antihyperglycemic agent for treatment of type II diabetes. Ann. Pharmacother. 30 (2), 158-164. doi: $10.1177 / 106002809603000210$

Melemedjian, O. K., Asiedu, M. N., Tillu, D. V., Sanoja, R., Yan, J., Lark, A., et al. (2011). Targeting adenosine monophosphate-activated protein kinase (AMPK) in preclinical models reveals a potential mechanism for the treatment of neuropathic pain. Mol. Pain 7, 70. doi: 10.1186/1744-8069-7-7

Melemedjian, O. K., Mejia, G. L., Lepow, T. S., Zoph, O. K., and Price, T. J. (2013a). Bidirectional regulation of $\mathrm{P}$ body formation mediated by eIF4F complex formation in sensory neurons. Neurosci. Lett. 563, 169-174. doi: 10.1016/ j.neulet.2013.09.048

Melemedjian, O. K., Yassine, H. N., Shy, A., and Price, T. J. (2013b). Proteomic and functional annotation analysis of injured peripheral nerves reveals ApoE as a protein upregulated by injury that is modulated by metformin treatment. Mol. Pain 9:14. doi: 10.1186/1744-8069-9-14

Miller, R. A., Chu, Q., Xie, J., Foretz, M., Viollet, B., and Birnbaum, M. J. (2013). Biguanides suppress hepatic glucagon signalling by decreasing production of cyclic AMP. Nature 494 (7436), 256-260. doi: 10.1038/nature11808

Mohamed, D., Elshahed, M. S., Nasr, T., Aboutaleb, N., and Zakaria, O. (2019). Novel LC-MS/MS method for analysis of metformin and canagliflozin in 
human plasma: application to a pharmacokinetic study. BMC Chem. 13 (1), 82. doi: 10.1186/s13065-019-0597-4

Müller, J., Lips, K. S., Metzner, L., Neubert, R. H., Koepsell, H., and Brandsch, M. (2005). Drug specificity and intestinal membrane localization of human organic cation transporters (OCT). Biochem. Pharmacol. 70 (12), 1851-1860. doi: 10.1016/j.bcp.2005.09.011

Muñoz-Arenas, G., Pulido, G., Treviño, S., Vázquez-Roque, R., Flores, G., Moran, C., et al. (2020). Effects of metformin on recognition memory and hippocampal neuroplasticity in rats with metabolic syndrome. Synapse 19, e22153. doi: $10.1002 /$ syn. 22153

Murasawa, H., Kobayashi, H., Saeki, K., and Kitano, Y. (2020). Anxiolytic effects of the novel $\alpha_{2} \delta$ ligand mirogabalin in a rat model of chronic constriction injury, an experimental model of neuropathic pain. Psychopharmacology 237 (1), 189197. doi: 10.1007/s00213-019-05356-3

Musi, N., Hirshman, M. F., Nygren, J., Svanfeldt, M., Bavenholm, P., Rooyackers, O., et al. (2002). Metformin increases AMP-activated protein kinase activity in skeletal muscle of subjects with type 2 diabetes. Diabetes 51 (7), 2074-2081. doi: 10.2337/diabetes.51.7.2074

Naranjo, C., Del Reguero, L., Moratalla, G., Hercberg, M., Valenzuela, M., and Failde, I. (2019). Anxiety, depression and sleep disorders in patients with diabetic neuropathic pain: a systematic review. Expert Rev. Neurother. 19 (12), 1201-1209. doi: 10.1080/14737175.2019.1653760

Narita, M., Kaneko, C., Miyoshi, K., Nagumo, Y., Kuzumaki, N., Nakajima, M., et al. (2006). Chronic pain induces anxiety with concomitant changes in opioidergic function in the amygdala. Neuropsychopharmacology 31 (4), 739750. doi: $10.1038 /$ sj.npp. 1300858

Ng, T. P., Feng, L., Yap, K. B., Lee, T. S., Tan, C. H., and Winblad, B. (2014). Longterm metformin usage and cognitive function among older adults with diabetes. J. Alzheimers Dis. 41 (1), 61-68. doi: 10.3233/JAD-131901

Nies, A. T., Koepsell, H., Winter, S., Burk, O., Klein, K., Kerb, R., et al. (2009). Expression of organic cation transporters OCT1 (SLC22A1) and OCT3 (SLC22A3) is affected by genetic factors and cholestasis in human liver. Hepatology 50 (4), 1227-1240. doi: 10.1002/hep.23103

Nikolaidis, S., Virgiliou, C., Vekiou, M., Skari, A., Kechagidou, A., Gika, H., et al. (2020). Effect of exercise on key pharmacokinetic parameters related to metformin absorption in healthy humans: A pilot study. Scand. J. Med. Sci. Sports 30 (5), 858-864. doi: 10.1111/sms.13628

Norsted-Gregory, E., Codeluppi, S., Gregory, J. A., Steinauer, J., and Svensson, C.II (2010). Mammalian target of rapamycin in spinal cord neurons mediates hypersensitivity induced by peripheral inflammation. Neuroscience 169 (3), 1392-1402. doi: 10.1016/j.neuroscience.2010.05.067

Nozu, T., Miyagishi, S., Kumei, S., Nozu, R., Takakusaki, K., and Okumura, T. (2019). Metformin inhibits visceral allodynia and increased gut permeability induced by stress in rats. J. Gastroenterol. Hepatol. 34 (1), 186-193. doi: 10.1111/ jgh.14367

Obara, I., Medrano, M. C., Signoret-Genest, J., Jiménez-Díaz, L., Géranton, S. M., and Hunt, S. P. (2015). Inhibition of the mammalian target of rapamycin complex 1 signaling pathway reduces itch behaviour in mice. Pain 156 (8), 1519-1529. doi: 10.1097/j.pain.0000000000000197

Ojeda, B., Dueñas, M., Salazar, A., Mico, J. A., Torres, L. M., and Failde, I. (2018). Factors influencing cognitive impairment in neuropathic and musculoskeletal pain and fibromyalgia. Pain Med. 19 (3), 499-510. doi: 10.1093/pm/pnx024

Owen, M. R., Doran, E., and Halestrap, A. P. (2000). Evidence that metformin exerts its anti-diabetic effects through inhibition of complex 1 of the mitochondrial respiratory chain. Biochem. J. 348 (3), 607-614. doi: 10.1042/ bj3480607

Paige, C., Mejia, G., Dussor, G., and Price, T. J. (2019). AMPK activation regulates P-body dynamics in mouse sensory neurons in vitro and in vivo. Neurobiol. Pain. 5:100026. doi: 10.1016/j.ynpai.2018.100026

Papanas, N., and Ziegler, D. (2012). Prediabetic neuropathy: does it exist? Curr. Diab. Rep. 12 (4), 376-383. doi: 10.1007/s11892-012-0278-3

Paul, D., Allakonda, L., and Satheeshkumar, N. (2017). A validated UHPLCQTOF-MS method for quantification of metformin and teneligliptin in rat plasma: application to pharmacokinetic interaction study. J. Pharm. Biomed. Anal. 143, 1-8. doi: 10.1016/j.jpba.2017.05.026

Pentikäinen, P. J., Neuvone, P. J., and Penttilä, A. (1979). Pharmacokinetics of metformin after intravenous and oral administration to man. Eur. J. Clin. Pharmacol. 16 (3), 195-202. doi: 10.1007/bf00562061
Pintana, H., Apaijai, N., Pratchayasakul, W., Chattipakorn, N., and Chattipakorn, S. C. (2012). Effects of metformin on learning and memory behaviors and brain mitochondrial functions in high-fat diet induced insulin resistant rats. Life Sci. 91 (11-12), 409-414. doi: 10.1016/j.lfs.2012.08.017

Piper, M., and Holt, C. (2004). RNA translation in axons. Ann. Rev. Cell Dev. Biol. 20, 505-523. doi: 10.1146/annurev.cellbio.20.010403.111746

Pop-Busui, R., Boulton, A. J., Feldman, E. L., Bril, V., Freeman, R., Malik, R. A., et al. (2017). Diabetic neuropathy: A position statement by the American Diabetes Association. Diabetes Care 40 (1), 136-154. doi: 10.2337/dc16-2042

Prakash, S., Rai, U., Kosuru, R., Tiwari, V., and Singh, S. (2020). Amelioration of diet-induced metabolic syndrome and fatty liver with Sitagliptin via regulation of adipose tissue inflammation and hepatic adiponectin/AMPK levels in mice. Biochimie 168, 198-209. doi: 10.1016/j.biochi.2019.11.005

Price, T. J., and Dussor, G. (2013). AMPK: An emerging target for modification of injury-induced pain plasticity. Neurosci. Lett. 557 PtA, 9-18. doi: 10.1016/ j.neulet.2013.06.060

Price, T. J., and Géranton, S. M. (2009). Translating nociceptor sensitivity: the role of axonal protein synthesis in nociceptor physiology. Eur. J. Neurosci. 29 (12), 2253-2263. doi: 10.1111/j.1460-9568.2009.06786.x

Price, T. J., Rashid, M. H., Millecamps, M., Sanoja, R., Entrena, J. M., and Cervero, F. (2007). Decreased nociceptive sensitization in mice lacking the fragile X mental retardation protein: role of mGluR1/5 and mTOR. J. Neurosci. 27 (51), 1395813967. doi: 10.1523/JNEUROSCI.4383-07.2007

Price, T. J., Das, V., and Dussor, G. (2016). Adenosine monophosphate-activated protein kinase (AMPK) activators for the prevention, treatment and potential reversal of pathological pain. Curr. Drug Targ. 17 (8), 908-920. doi: 10.2174/ 1389450116666151102095046

Raab-Graham, K. F., Haddick, P. C., Jan, Y. N., and Jan, L. Y. (2006). Activity-and mTOR-dependent suppression of Kv1. 1 channel mRNA translation in dendrites. Science 314 (5796), 144-148. doi: 10.1126/science.1131693

Rasgon, N. L., and Kenna, H. A. (2005). Insulin resistance in depressive disorders and Alzheimer's disease: revisiting the missing link hypothesis. Neurobiol. Aging 26 (1), 103-107. doi: 10.1016/j.neurobiolaging.2005.09.004

Rena, G., Hardie, D. G., and Pearson, E. R. (2017). The mechanisms of action of metformin. Diabetologia 60 (9), 1577-1585. doi: 10.1007/s00125-017-4342-z

Russe, O. Q., Möser, C. V., Kynast, K. L., King, T. S., Stephan, H., Geisslinger, G., et al. (2013). Activation of the AMP-activated protein kinase reduces inflammatory nociception. J. Pain 14 (11), 1330-1340. doi: 10.1016/j.jpain.2013.05.012

Sambol, N. C., Chiang, J., O’Conner, M., Liu, C. Y., Lin, E. T., Goodman, A. M., et al. (1996). Pharmacokinetics and pharmacodynamics of metformin in healthy subjects and patients with noninsulin-dependent diabetes mellitus. J. Clin. Pharmacol. 36 (11), 1012-1021. doi: 10.1177/009127009603601105

Sato, T., Masuda, S., Yonezawa, A., Tanihara, Y., Katsura, T., and Inui, K. (2008). Transcellular transport of organic cations in double-transfected MDCK cells expressing human organic cation transporters hOCT1/hMATE1 and hOCT2/ hMATE1. Biochem. Pharmacol. 76 (7), 894-903. doi: 10.1016/j.bcp. 2008.07.005

Schachter, C. L., Busch, A. J., Peloso, P. M., and Sheppard, M. S. (2003). Effects of short versus long bouts of aerobic exercise in sedentary women with fibromyalgia: a randomized controlled trial. Phys. Ther. 83 (4), 340-358. doi: $10.1093 / \mathrm{ptj} / 83.4 .340$

Scheen, A. J., and Paquot, N. (2012). Gliptin versus a sulphonylurea as add-on to metformin. Lancet 380 (9840), 450-452. doi: 10.1016/S0140-6736(12)60859-9

Scheen, A. J. (1996). Clinical pharmacokinetics of metformin. Clin. Pharmacokinet. 30 (5), 359-371. doi: 10.2165/00003088-199630050-00003

Sharma, S., and Fulton, S. (2013). Diet-induced obesity promotes depressive-like behaviour that is associated with neural adaptations in brain reward circuitry. Int. J. Obes. 37 (3), 382-389. doi: 10.1038/ijo.2012.48

Shaw, R. J., Kosmatka, M., Bardeesy, N., Hurley, R. L., Witters, L. A., DePinho, R. A., et al. (2004). The tumor suppressor LKB1 kinase directly activates AMP-activated kinase and regulates apoptosis in response to energy stress. Proc. Natl. Acad. Sci. U.S.A. 101 (10), 3329-3335. doi: 10.1073/pnas.0308061100

Shaw, R. J., Lamia, K. A., Vasquez, D., Koo, S. H., Bardeesy, N., DePinho, R. A., et al. (2005). The kinase LKB1 mediates glucose homeostasis in liver and therapeutic effects of metformin. Science 310 (5754), 1642-1646. doi: 10.1126/ science.1120781

Shiers, S., Pradhan, G., Mwirigi, J., Mejia, G., Ahmad, A., Kroener, S., et al. (2018). Neuropathic pain creates an enduring prefrontal cortex dysfunction corrected 
by the type II diabetic drug metformin but not by gabapentin. J. Neurosci. 38 (33), 7337-7350. doi: 10.1523/JNEUROSCI.0713-18.2018

Shuai, Y., Li, C., and Zhou, X. (2020). The effect of metformin on gastric cancer in patients with type 2 diabetes: a systematic review and meta-analysis. Clin. Transl. Oncol. 22, 1580-1590. doi: 10.1007/s12094-020-02304-y

Sieberg, C. B., Taras, C., Gomaa, A., Nickerson, C., Wong, C., Ward, C., et al. (2018). Neuropathic pain drives anxiety behavior in mice, results consistent with anxiety levels in diabetic neuropathy patients. Pain Rep. 3 (3), e651. doi: 10.1007/s12094-020-02304-y

Sirtori, C. R., Franceschini, G., Galli-Kienle, M., Cighetti, G., Galli, G., Bondioli, A., et al. (1978). Disposition of metformin (N, N-dimethylbiguanide) in man. Clin. Pharmacol. Ther. 24 (6), 683-693. doi: 10.1002/cpt1978246683

Slivicki, R. A., Mali, S. S., and Hohmann, A. G. (2019). Voluntary exercise reduces both chemotherapy-induced neuropathic nociception and deficits in hippocampal cellular proliferation in a mouse model of paclitaxel-induced peripheral neuropathy. Neurobiol. Pain 6, 100035. doi: 10.1016/j.ynpai. 2019.100035

Stamboulian, S., Choi, J. S., Ahn, H. S., Chang, Y. W., Tyrrell, L., Black, J. A., et al. (2010). ERK1/2 mitogen-activated protein kinase phosphorylates sodium channel Nav1.7 and alters its gating properties. J. Neurosci. 30 (5), 16371647. doi: 10.1523/JNEUROSCI.4872-09.2010

Stepensky, D., Friedman, M., Raz, I., and Hoffman, A. (2002). Pharmacokineticpharmacodynamic analysis of the glucose-lowering effect of metformin in diabetic rats reveals first-pass pharmacodynamic effect. Drug Metab. Dispos. 30 (8), 861-868. doi: 10.1124/dmd.30.8.861

Sterne, J. (1957). Du nouveau dans les antidiabetiques. La NN dimethylamine guanyl guanide (NNDG). Maroc. Med. 36, 1295-1296.

Stino, A. M., and Smith, A. G. (2017). Peripheral neuropathy in prediabetes and the metabolic syndrome. J. Diabetes Investig. 8 (5), 646-655. doi: 10.1111/ jdi. 12650

Stumvoll, M., Chintalapudi, U., Perriello, G., Welle, S., Gutierrez, O., and Gerich, J. (1995). Uptake and release of glucose by the human kidney. Postabsorptive rates and responses to epinephrine. J. Clin. Invest. 96 (5), 2528-2533. doi: 10.1172/ JCI118314

Sun, L., Kwok, E., Gopaluni, B., and Vahidi, O. (2011). Pharmacokineticpharmacodynamic modeling of metformin for the treatment of type II diabetes mellitus. Open Biomed. Eng. J. 5, 1-7. doi: 10.2174/187412070 1105010001

Takei, N., Inamura, N., Kawamura, M., Kawamura, M., Namba, H., Yonezawa, K., et al. (2004). Brain-derived neurotrophic factor induces mammalian target of rapamycin-dependent local activation of translation machinery and protein synthesis in neuronal dendrites. J. Neurosci. 24 (44), 9760-9769. doi: 10.1523/ JNEUROSCI.1427-04.2004

Takemori, H., Hamamoto, A., Isogawa, K., Ito, M., Takagi, M., Morino, H., et al. (2020). Mouse model of metformin-induced diarrhea. BMJ Open Diabetes Res. Care 8 (1), e000898. doi: 10.1136/bmjdrc-2019-000898

Tanaka, K., Saisho, Y., Kawai, T., Tanaka, M., Meguro, S., Irie, J., et al. (2015). Efficacy and safety of liraglutide monotherapy compared with metformin in Japanese overweight/obese patients with type 2 diabetes. Endocr. J. 62 (5), 399409. doi: 10.1507/endocrj.EJ14-0602

Taylor, A., Westveld, A. H., Szkudlinska, M., Guruguri, P., Annabi, E., Li, Z., et al. (2013). The use of metformin is associated with decreased lumbar radiculopathy pain. J. Pain Res. 6, 755-763. doi: 10.2147/JPR.S52205

Tillu, D. V., Melemedjian, O. K., Asiedu, M. N., Qu, N., De Felice, M., Dussor, G., et al. (2012). Resveratrol engages AMPK to attenuate ERK and mTOR signaling in sensory neurons and inhibits incision-induced acute and chronic pain. Mol. Pain. 8:5. doi: 10.1186/1744-8069-8-5

Trinh, M. A., and Klann, E. (2013). Translational control by eIF2 $\alpha$ kinases in longlasting synaptic plasticity and long-term memory. Neurobiol. Learn. Mem. 105, 93-99. doi: 10.1016/j.nlm.2013.04.013

Tsuda, M., Terada, T., Mizuno, T., Katsura, T., Shimakura, J., and Inui, K. (2009). Targeted disruption of the multidrug and toxin extrusion 1 (MATE1) gene in mice reduces renal secretion of metformin. Mol. Pharmacol. 75 (6), 1280-1286. doi: 10.1124/mol.109.056242

Tucker, G. T., Casey, C., Phillips, P. J., Connor, H., Ward, J. D., and Woods, H. F. (1981). Metformin kinetics in healthy subjects and in patients with diabetes mellitus. Br. J. Clin. Pharmacol. 12 (2), 235-246. doi: 10.1111/j.13652125.1981.tb01206.x
Tzatsos, A., and Kandror, K. V. (2006). Nutrients suppress phosphatidylinositol 3 kinase/Akt signaling via raptor-dependent mTOR-mediated insulin receptor substrate 1 phosphorylation. Mol. Cell Biol. 26 (1), 63-76. doi: 10.1128/ MCB.26.1.63-76.2006

UK Prospective Diabetes Study (UKPDS) Group (1998). Effect of intensive bloodglucose control with metformin on complications in overweight patients with type 2 diabetes (UKPDS 34). Lancet 352 (9131), 854-865. doi: 10.1016/S01406736(98)07037-8

Uttam, S., Wong, C., Price, T. J., and Khoutorsky, A. (2018). eIF4E-dependent translational control: A central mechanism for regulation of pain plasticity. Front. Genet. 9, 470. doi: 10.3389/fgene.2018.00470

Vigneri, R., and Goldfine, I. D. (1987). Role of metformin in treatment of diabetes mellitus. Diabetes Care 10 (1), 118-122. doi: 10.2337/diacare.10.1.118

Wang, X., Zhang, G., Jia, M., Xie, Z. M., Yang, J. J., Shen, J. C., et al. (2019). Environmental enrichment improves pain sensitivity, depression-like phenotype, and memory deficit in mice with neuropathic pain: role of NPAS4. Psychopharmacology 236 (7), 1999-2014. doi: 10.1007/s00213-019-5187-6

Wei, S. Y., Yeh, H. H., Liao, F. F., and Chen, S. H. (2009). CE with direct sample injection for the determination of metformin in plasma for type 2 diabetic mellitus: An adequate alternative to HPLC. J. Sep. Sci. 32 (3), 413-421. doi: 10.1002/ jssc. 200800463

Wei, J. Y., Liu, C. C., Ouyang, H. D., Ma, C., Xie, M. X., Liu, M., et al. (2017). Activation of RAGE/STAT3 pathway by methylglyoxal contributes to spinal central sensitization and persistent pain induced by bortezomib. Exp. Neurol. 296, 74-82. doi: 10.1016/j.expneurol.2017.07.010

Weng, W., Yao, C., Poonit, K., Zhou, X., Sun, C., Zhang, F., et al. (2019). Metformin relieves neuropathic pain after spinal nerve ligation via autophagy flux stimulation. J. Cell Mol. Med. 23 (2), 1313-1324. doi: 10.1111/jcmm.14033

Winder, W. A., and Hardie, D. G. (1999). AMP-activated protein kinase, a metabolic master switch: possible roles in type 2 diabetes. Am. J. Physiol. Endocrinol. Metabol. 277 (1), E1-E10. doi: 10.1152/ajpendo.1999.277

Won, S., Park, K., Lim, H., and Lee, S. J. (2020). Sexual dimorphism in cognitive disorders in a murine model of neuropathic pain. Behav. Brain Funct. 16 (1), 1. doi: 10.1186/s12993-019-0164-0

Woods, A., Johnstone, S. R., Dickerson, K., Leiper, F. C., Fryer, L. G., Neumann, D., et al. (2003). LKB1 is the upstream kinase in the AMP-activated protein kinase cascade. Curr. Biol. 13 (22), 2004-2008. doi: 10.1016/j.cub.2003.10.031

Wu, B., Chen, M., Gao, Y., Hu, J., Liu, M., Zhang, W., et al. (2019). In vivo pharmacodynamic and pharmacokinetic effects of metformin mediated by the gut microbiota in rats. Life Sci. 226, 185-192. doi: 10.1016/j.lfs.2019.04.009

Xiang, H. C., Lin, L. X., Hu, X. F., Zhu, H., Li, H. P., Zhang, R. Y., et al. (2019). AMPK activation attenuates inflammatory pain through inhibiting NF- $\mathrm{KB}$ activation and IL-1 $\beta$ expression. J. Neuroinflamm. 16 (1), 34. doi: 10.1186/s12974-019-1411-x

Xiao, B., Heath, R., Saiu, P., Leiper, F. C., Leone, P., Jing, C., et al. (2007). Structural basis for AMP binding to mammalian AMP-activated protein kinase. Nature 449 (7161), 496-500. doi: 10.1038/nature06161

Xing, X., Wu, K., Dong, Y., Zhou, Y., Zhang, Y., Jiang, F., et al. (2020). Hyperactive Akt-mTOR pathway as a therapeutic target for pain hypersensitivity in Cntnap2-deficient mice. Neuropharmacology 165, 107816. doi: 10.1016/ j.neuropharm.2019.107816

Yadav, S. K., Nagori, B. P., and Desai, P. K. (2014). Pharmacological characterization of different fractions of Calotropis procera (Asclepiadaceae) in streptozotocin induced experimental model of diabetic neuropathy. J. Ethnopharmacol. 152 (2), 349-357. doi: 10.1016/j.jep.2014.01.020

Yalcin, I., Bohren, Y., Waltisperger, E., Sage-Ciocca, D., Yin, J. C., Freund-Mercier, M. J., et al. (2011). A time-dependent history of mood disorders in a murine model of neuropathic pain. Biol. Psychiatry 70 (10), 946-953. doi: 10.1016/ j.biopsych.2011.07.017

Yu, B., Pugazhenthi, S., and Khandelwal, R. L. (1994). Effects of metformin on glucose and glucagon regulated gluconeogenesis in cultured normal and diabetic hepatocytes. Biochem. Pharmacol. 48 (5), 949-954. doi: 10.1016/ 0006-2952(94)90365-4

Zemdegs, J., Quesseveur, G., Jarriault, D., Pénicaud, L., Fioramonti, X., and Guiard, B. P. (2016). High-fat diet-induced metabolic disorders impairs 5HT function and anxiety-like behavior in mice. Br. J. Pharmacol. 173 (13), 2095-2110. doi: 10.1111/bph.13343

Zemdegs, J., Martin, H., Pintana, H., Bullich, S., Manta, S., Marqués, M. A., et al. (2019). Metformin promotes anxiolytic and antidepressant-like responses in 
insulin-resistant mice by decreasing circulating branched-chain amino acids. J. Neurosci. 39 (30), 5935-5948. doi: 10.1523/JNEUROSCI.2904-18.2019

Zhang, X., Peng, Y., Wan, P., Yin, L., Wang, G., and Sun, J. (2014). Simultaneous determination and pharmacokinetic study of metformin and pioglitazone in dog plasma by LC-MS-MS. J. Chromatogr. Sci. 52 (1), 52-58. doi: 10.1093/ chromsci/bms204

Zhang, D., Xuan, J., Zheng, B. B., Zhou, Y. L., Lin, Y., Wu, Y. S., et al. (2017). Metformin improves functional recovery after spinal cord injury via autophagy flux stimulation. Mol. Neurobiol. 54 (5), 3327-3341. doi: 10.1007/s12035-0169895-1

Zhang, M., Feng, R., Yue, J., Qian, C., Yang, M., Liu, W., et al. (2020). Effects of metformin and sitagliptin monotherapy on expression of intestinal and renal sweet taste receptors and glucose transporters in a rat model of type 2 diabetes. Horm. Metab. Res. 52 (5), 329-335. doi: 10.1055/a-1135-9031

Zhou, G., Myers, R., Li, Y., Chen, Y., Shen, X., Fenyk-Melody, J., et al. (2001). Role of AMP-activated protein kinase in mechanism of metformin action. J. Clin. Invest. 108 (8), 1167-1174. doi: 10.1172/JCI13505

Zhou, M., Xia, L., and Wang, J. (2007). Metformin transport by a newly cloned proton-stimulated organic cation transporter (plasma membrane monoamine transporter) expressed in human intestine. Drug Metab. Dispos. 35 (10), 19561962. doi: 10.1124/dmd.107.015495

Zhou, W., Kavelaars, A., and Heijnen, C. J. (2016). Metformin prevents cisplatininduced cognitive impairment and brain damage in mice. PloS One 11 (3), e0151890. doi: 10.1371/journal.pone.0151890
Zhou, W., Jin, Y., Meng, Q., Zhu, X., Bai, T., Tian, Y., et al. (2019). A neural circuit for comorbid depressive symptoms in chronic pain. Nat. Neurosci. 22, 16491658. doi: 10.1038/s41593-019-0468-2

Ziegler, D., Rathmann, W., Dickhaus, T., Meisinger, C., and Mielck, A. (2008). Prevalence of polyneuropathy in pre-diabetes and diabetes is associated with abdominal obesity and macroangiopathy: the MONICA/KORA Augsburg Surveys S2 and S3. Diabetes Care 31 (3), 464-469. doi: 10.2337/ dc07-1796

Ziegler, D., Movsesyan, L., Mankovsky, B., Gurieva, I., Abylaiuly, Z., and trokov, I. (2009). Treatment of symptomatic polyneuropathy with actovegin in type 2 diabetic patients. Diabetes Care 32 (8), 1479-1484. doi: 10.2337/ dc09-0545

Conflict of Interest: The authors declare that the research was conducted in the absence of any commercial or financial relationships that could be construed as a potential conflict of interest.

Copyright (C) 2020 Baeza-Flores, Guzmán-Priego, Parra-Flores, Murbartián, TorresLópez and Granados-Soto. This is an open-access article distributed under the terms of the Creative Commons Attribution License (CC BY). The use, distribution or reproduction in other forums is permitted, provided the original author(s) and the copyright owner(s) are credited and that the original publication in this journal is cited, in accordance with accepted academic practice. No use, distribution or reproduction is permitted which does not comply with these terms. 